\title{
Chaperoning 5S RNA assembly
}

\author{
Clément Madru, ${ }^{1,5}$ Simon Lebaron, ${ }^{1,2,5}$ Magali Blaud, ${ }^{1}$ Lila Delbos, ${ }^{1}$ Juliana Pipoli, ${ }^{3}$ Eric Pasmant, ${ }^{4}$ \\ Stéphane Réty, ${ }^{1}$ and Nicolas Leulliot ${ }^{1}$ \\ ${ }^{1}$ Laboratoire de Cristallographie et RMN Biologiques, UMR, CNRS 8015, Université Paris Descartes, Faculté de Pharmacie, \\ Sorbonne Paris Cité, 75006 Paris, France; ${ }^{2}$ CR2 INSERM; ${ }^{3}$ Plateforme Génomique, Institut Cochin, UMR_S1016, INSERM, 75006 \\ Paris, France; ${ }^{4}$ Service de Biochimie et Génétique Moléculaire, Hôpital Cochin, Assistance Publique-Hôpitaux de Paris, 75006 \\ Paris, France
}

In eukaryotes, three of the four ribosomal RNAs (rRNAs) - the 5.8S, 18S, and 25S/28S rRNAs-are processed from a single pre-rRNA transcript and assembled into ribosomes. The fourth rRNA, the 5S rRNA, is transcribed by RNA polymerase III and is assembled into the $5 \mathrm{~S}$ ribonucleoprotein particle (RNP), containing ribosomal proteins Rpl5/ $\mathrm{uL18}$ and Rpl11/uL5, prior to its incorporation into preribosomes. In mammals, the 5S RNP is also a central regulator of the homeostasis of the tumor suppressor p53. The nucleolar localization of the 5S RNP and its assembly into preribosomes are performed by a specialized complex composed of Rpf2 and Rrs1 in yeast or Bxdc1 and hRrs1 in humans. Here we report the structural and functional characterization of the Rpf2-Rrs1 complex alone, in complex with the 5S RNA, and within pre-60S ribosomes. We show that the Rpf2-Rrs1 complex contains a specialized 5S RNA E-loop-binding module, contacts the Rpl5 protein, and also contacts the ribosome assembly factor Rsa4 and the 25S RNA. We propose that the Rpf2-Rrs1 complex establishes a network of interactions that guide the incorporation of the 5S RNP in preribosomes in the initial conformation prior to its rotation to form the central protuberance found in the mature large ribosomal subunit.

[Keywords: 5S RNP; ribosome assembly; p53; Brix domain]

Supplemental material is available for this article.

Received February 13, 2015; revised version accepted June 2, 2015.

The production of ribosomes is one of the most energyconsuming processes in eukaryotic cells. Ribosome biogenesis is a highly organized and regulated pathway that requires the sequential action of $>200$ nonribosomal factors (Gamalinda et al. 2014). Ribosome biogenesis starts by the transcription of a pre-RNA precursor in the nucleolus, a specialized non-membrane-bound nuclear compartment. Three of the four ribosomal RNAs (rRNAs)the $5.8 \mathrm{~S}, 18 \mathrm{~S}$, and $25 \mathrm{~S}$ rRNAs-are cotranscribed as a single $35 \mathrm{~S}$ precursor by polymerase I. This precursor is cotranscriptionally modified, folded, cleaved, and assembled with both ribosomal proteins and nonribosomal factors to generate the mature ribosomes. During ribosome production, preribosomal particles are exported first to the nucleus and then to the cytoplasm. The final maturation step occurs in a translation-like cycle involving the pre-40S complex and the mature 60S subunit (Lebaron et al. 2012; Strunk et al. 2012). The production of ribosomes has been suggested to be a sequential series of quality control steps that block and recycle nonoptimally assembled preribosomes. Defects in the ribosome assembly pathway have been identified in a number of inherited

\footnotetext{
${ }^{5}$ These authors contributed equally to this work. Corresponding authors: nicolas.leulliot@parisdescartes.fr, simon.lebaron@ parisdescartes.fr

Article is online at http://www.genesdev.org/cgi/doi/10.1101/gad.260349. 115 .
}

hematopoietic disorders, collectively called ribosomopathies, which have been linked to progression into cancer (Armistead et al. 2009; Narla and Ebert 2011; Sondalle and Baserga 2014).

In contrast to the $5.8 \mathrm{~S}, 18 \mathrm{~S}$, and $25 / 28 \mathrm{~S}$ rRNAs, the maturation of 5S RNA follows a totally different pathway before incorporation into preribosomes. The 5S rRNA is transcribed by a different polymerase (RNA polymerase III) at a locus not associated with nucleoli in metazoans or located in proximity to the nucleolus in yeast and has to be imported into the nucleolus for integration in preribosomal particles. A significant fraction of the 5S rRNA in the cell is not associated with ribosomes (Knight and Darnell 1967; Sloan et al. 2013) and has been shown to interact with several proteins (for review, see Ciganda and Williams 2011). The La protein binds immature 5S RNA containing additional uridines at the $3^{\prime}$ terminus. The transcription factor TFIIIA, which binds the 5S rDNA and activates its transcription, also binds 5S RNA to form a $7 \mathrm{~S}$ ribonucleoprotein particle (RNP) in several organisms (for review, see Layat et al. 2013). In Xenopus

(C) 2015 Madru et al. This article is distributed exclusively by Cold Spring Harbor Laboratory Press for the first six months after the full-issue publication date (see http://genesdev.cshlp.org/site/misc/terms.xhtml). After six months, it is available under a Creative Commons License (Attribution-NonCommercial 4.0 International), as described at http:// creativecommons.org/licenses/by-nc/4.0/. 
oocytes, the 7S RNP is found in the cytoplasm; TFIIIA protects the RNA from degradation and "stores" the 5S RNA for later assembly into ribosomes.

The 5S rRNA associates with the Rpl5 and Rpl11 proteins (also referred to as uL18 and uL5), the main 5S rRNA-interacting proteins in mature ribosomes, prior to its incorporation into ribosomes (Steitz et al. 1988; Zhang et al. 2007; Sloan et al. 2013). Rpl5 and Rpl11 are imported and probably assembled on the 5S RNA by the specialized importin Syol (Calviño et al. 2015). The 5S RNP has recently been found to be a major actor in the p53-MDM2 regulation pathway in humans. MDM2 is an E3 ubiquitin ligase that ubiquitinates $\mathrm{p} 53$ and targets it for proteasomal degradation. The 5S RNP binds to and inhibits MDM2, resulting in the stabilization and activation of $\mathrm{p} 53$. This pathway regulates energy metabolism, senses nucleolar stress such as impairment of ribosome biogenesis, and is an essential control for oncogene overexpression (Donati et al. 2013; Sloan et al. 2013; Liu et al. 2014). The regulation of the $5 \mathrm{~S} \mathrm{RNP} / \mathrm{p} 53$ pathway plays a major role in ribosomopathies, such as Diamond Blackfan anemia, 5q syndrome, and Treacher Collins syndrome, which are believed to be caused by the misregulation of $\mathrm{p} 53$. As a master regulator of the tumor suppressor p53 and ribosome biogenesis, the 5S RNP pathway is therefore a promising therapeutic target for the treatment of both cancer and ribosomopathies (Miliani de Marval and Zhang 2011; Sasaki et al. 2011).

Assembly of the 5S RNP into preribosomes requires two nonribosomal proteins: Rpf2 (Bxdc1 in humans) and Rrs1 (Zhang et al. 2007). These factors form a binary complex and interact with the 5S RNP to form the complex that is incorporated into preribosomes. Rpf2/Bxdc1 contains a Brix domain that is found in a family of proteins involved in ribosome biogenesis that includes Rpf1, Imp4, Brixl, and Ssf1/Ssf2 (Wehner and Baserga 2002). The Brix domain is predicted to be an RNA-binding motif, although no specific RNA target has been determined so far for any of the family members. The structure and function of Rrs1 are unknown. Depletion of Rpf2/Bxdc1 or $\mathrm{Rrs} 1 / \mathrm{hRrs} 1$ leads to a processing defect of the large ribosomal subunit rRNAs, mislocalization of Rpl5/Rpl11, impairment of 5S RNP recruitment into preribosomes, and impairment of nuclear export of preribosomes (Zhang et al. 2007; Donati et al. 2013; Sloan et al. 2013). The cryo-electron microscopy (cryo-EM) structure of late pre$60 \mathrm{~S}$ particles has shown that the central protuberance (CP), which contains the 5S RNP, is structurally very different from that found in the mature ribosome (Leidig et al. 2014). In the preribosome, the 5S RNP is docked to helix 84 in the $25 \mathrm{~S}$ rRNA but is rotated by $\sim 180^{\circ}$ relative to its position in the mature $60 \mathrm{~S}$ complex. The conformational state of the 5S RNP in the preribosome is locked by the ribosome biogenesis factor Rsa4, which interacts with Rpl5/uL18 and the 25S rRNA. Remodeling of the CP to generate the conformation present in the mature $60 \mathrm{~S}$ subunit and removal of Rsa4 is performed by the dynein-related AAA ATPase Real (Baßler et al. 2014) and is coupled to the action of the Nug2 GTPase to generate an export-competent particle (Matsuo et al. 2014).
In this study, we set out to elucidate the function of the Rpf2-Rrs1 complex in the incorporation of the $5 \mathrm{~S}$ RNP into preribosomes. We solved the structure of the Rpf2-Rrs1 complex alone, bound to 5S RNA, and within pre-60S particles using X-ray crystallography and small angle X-ray scattering in solution (SAXS) and fitting these structures to pre-60S cryo-EM envelopes. These structural studies, complemented by in vivo and in vitro study of RNA and protein interactions, enable us to propose a model for the function of Rpf2-Rrs1 in ribosome biogenesis.

\section{Results}

Structure solution of the Rpf2-Rrs1 complex

The full-length yeast Rpf2-Rrs1 proteins were expressed in a bacterial system using a polycistronic construct. A two-step purification procedure using nickel affinity purification (Rpf2 was expressed with an $\mathrm{N}$-terminal histidine tag) followed by size exclusion chromatography yielded a sample purified to homogeneity that was suitable for structural studies (Supplemental Fig. S1). However, no crystals were obtained using the full-length Rpf2-Rrs1 proteins. This was likely due to the presence of unstructured regions in the $\mathrm{N}$-terminal and $\mathrm{C}$-terminal regions of both proteins. Limited trypsin proteolysis identified a stable structural core comprising both Rpf2 and Rrs1 (Supplemental Fig. S1). This sample crystallized under several of the tested conditions without any further purification. The structure was phased at $3.4 \AA$ A resolution by single isomorphous replacement with anomalous scattering using a platinum derivative and was further refined to $2.4 \AA$ A resolution in a nonisomorphous native data set. Data collection and refinement statistics are reported in Table 1.

The Rpf2 and Rrs1 proteins are present in a 1:1 complex (Fig. 1) in agreement with the elution volume from size exclusion chromatography and molecular weight derived from SAXS data (see later). The final model includes the conserved domains identified by sequence analysis for both Rpf2 and Rrs1, and the residues observed are consistent with the fragments identified by mass spectrometry analysis of the proteolyzed sample. The crystallized Rpf2 fragment is a single polypeptide chain spanning residues $23-252$, with missing electron density for the $\beta_{9}-\beta_{10}$ loop (residues 212-216), englobing the predicted Brix domain (32-237) (Supplemental Fig. S1). The Rrs1 fragment contained residues 9-106, with missing density for the $\beta_{4}-\beta_{5}$ loop (residues 74-84) (Supplemental Fig. S1).

The Rpf2 structure shows the same overall $\alpha-\beta-\alpha-\beta$ sandwich fold as the archaeal Brix domain protein Mth680 (9\% sequence identity) (Ng et al. 2005) and superposes with $3 \AA$ root mean square deviation over 180 residues. As in the archaeal protein, the structure is composed of an extended $U$-shaped $\beta$ sheet forming a taco shell-shaped structure (Fig. 1). This sheet forms two layers: The first $\beta$ layer (L1) (light blue in Fig. 1) is formed by the $\beta_{2}-\beta_{1}-\beta_{3}-\beta_{4}-\beta_{5}-\beta_{10 b}$ strands, and the second $\beta$ layer (L2) (dark blue in Fig. 1) is formed by the $\beta_{6}-\beta_{8}-\beta_{9}-\beta_{10 a}$ strands. $\beta_{10}$ forms an extended strand that spans and 
Table 1. X-ray diffraction statistics

\begin{tabular}{lccc}
\hline & Native & PtCl6 & PtCl4 \\
\hline Wavelength & $0.934 \AA$ & $1.0716 \AA$ & $1.0716 \AA$ \\
Resolution & $45.51-2.40$ & $45.51-3.40$ & $48.72-4.01$ \\
Space group & $\mathrm{P} 43212$ & $\mathrm{P} 43212$ & $\mathrm{P} 43212$ \\
Unit cell & $72.28 \AA, 72.28 \AA, 175.71 \AA$ & $72.28 \AA, 72.28 \AA, 175.71 \AA$ & $72.28 \AA, 72.28 \AA, 175.71 \AA$ \\
Total reflections & $217,634(20,401)$ & $49,898(4494)$ & $32,462(2861)$ \\
Unique reflections & $18,921(1811)$ & $6270(585)$ & $4141(363)$ \\
Multiplicity & $11.5(11.3)$ & $8.0(7.7)$ & $7.8(7.9)$ \\
Completeness & $99.72 \%(97.52 \%)$ & $92.83 \%(90.56 \%)$ & $98.85 \%(92.84 \%)$ \\
Mean I/ $/ \mathrm{I})$ & $17.82(1.92)$ & $19.19(4.01)$ & $21.51(4.69)$ \\
Solvent content & $52.80 \%$ & $0.084(0.57)$ & $0.097(0.60)$ \\
$R$-merge & $0.098(1.09)$ & $0.998(0.776)$ & $0.999(0.936)$ \\
CC $1 / 2$ & $0.999(0.680)$ & $0.999(0.935)$ & $1(0.983)$ \\
CC* & $1(0.9)$ & & \\
$R$-work & $0.19(0.28)$ & & \\
$R$-free & $0.23(0.35)$ & & \\
RMS (bonds) & 0.009 & & \\
RMS (angles) & $1.17^{\circ}$ & & \\
Ramachandran favored & $97 \%$ & & \\
Ramachandran allowed & $3 \%$ & & \\
\hline
\end{tabular}

connects the two layers. The central $\alpha$-helical layer filling the taco shell is composed of the $\alpha_{1}$ and $\alpha_{3}$ helices inserted between the first and the second strand in each $\beta$ layer $\left(\beta_{1}-\beta_{2}\right.$ and $\left.\beta_{6}-\beta_{8}\right)$. The $\alpha_{2}$ helix inserted between the $\beta_{2}-\beta_{3}$ strands packs on the outward face of $\beta$ layer L1. No structural homologs could be identified for Rrs1.

\section{Rpf2 and Rrs1 form an intimate complex}

The Rpf2-Rrs1 complex forms an unexpected and surprising structure where the structural elements of Rrs1 extend the Rpf $2 \beta$ sheets. Rrs1 is composed of a long a helix $\left(\alpha_{1^{\prime}}\right)$ at the $N$ terminus and four $\beta$ strands $\left(\beta_{1^{\prime}}\right.$ to $\beta_{4^{\prime}}$. The $\beta_{1^{\prime}}$ and $\beta_{2^{\prime}}$ strands extend the Rpf $2 \beta$ layer L 2 after the Rpf $2 \beta_{6}$ strand (Fig. 1C). The Rrs $1 \alpha_{1^{\prime}}$ helix packs on the exterior of this extended $\beta$ layer L2 (Fig. 1B). The Rrs1 $\beta_{3^{\prime}}$ and $\beta_{4^{\prime}}$ strands form an additional $\beta$ sheet with the Rpf2 $\beta_{7}$ strand and pack on the $C$ terminus of the $\alpha_{1^{\prime}}$ helix.

The structure of the archaeal protein Mth680 revealed that Brix domains harbor an internal duplication of an $\alpha-\beta$ layer related by a twofold symmetry, indicating that the Brix family proteins could have arisen from a gene duplication and fusion event ( $\mathrm{Ng}$ et al. 2005). This duplicated unit, hereafter called the Brix internal duplicated (BID) domain, corresponds to the two halves of the taco shell (colored light and dark blue in Fig. 1). The BID domain is structurally homologous to the anti-codon loop-binding domain of class IIa aminoacyl-tRNA synthetases (aaRSs) (Ng et al. 2005). A remarkable feature of the Rpf2-Rrs1 complex is that Rrs1 completes the structure of the Rpf2 BID domain. Indeed, superposition of the two $\beta$ layers reveals that the Rrs $1 \beta_{2}$, strand in $\beta$ layer L2 mirrors the position of Rpf2 $\beta_{2}$ in $\beta$ layer L1 (i.e., the $\beta_{2}-\beta_{1}-\beta_{3}-\beta_{4}-\beta_{5}$ layer superposes with the $\beta_{2^{\prime}}-\beta_{6}-\beta_{8}-\beta_{9}-$ $\beta_{10 a}$ strands) (Fig. 1D). In contrast, in the Mth680 protein, the $\beta_{7}$ strand completes the L2 $\beta$ layer before $\beta_{6}$, while the $\operatorname{Rpf} 2 \beta_{7}$ is looped out and forms the extra $\beta$ sheet with the
Rrs $1 \beta_{3^{\prime}}$ and $\beta_{4^{\prime}}$ strands (Fig. 1D). The structural change in the topology of the $\beta$ layer L2 could be induced by Rrs1 binding.

In addition, Rrs 1 extends the BID domain by providing an extra $\alpha$-helical layer. Superposition of the two $\beta$ layers in Rpf 2 and Mth680 shows that the $\alpha_{1}$ and $\alpha_{3}$ helices composing the central $\alpha$ layer in the taco shell (Fig. 1D) are structural equivalents: They superpose in the same region and are inserted between equivalent $\beta$ strands. However, in the CTDs of both Mth680 and Rpf2, there is no equivalent $\alpha$ helix to $\alpha_{2}$, which packs on the exterior surface of $\beta$ layer L1. In the Rpf2-Rrs1 complex, the Rrs $1 \alpha_{1^{\prime}}$ helix packs on the exterior face of $\beta$ layer L2 in the same position and orientation as $\alpha_{2}$ (Fig. 1D). Moreover, $\alpha_{1^{\prime}}$ follows the $\beta_{2^{\prime}}$ strand in L2, equivalent to $\beta_{2}$ in L1. This structural and topological analogy defines $\alpha_{1^{\prime}}$ as a structural equivalent to the $\alpha_{2}$ helix and extends the duplicated BID domain to the entire $\alpha-\beta-\alpha$ layer. Recently, the crystal structure of the Rpf2-Rrs1 complex from Aspergillus nidulans has been reported (Asano et al. 2015). Despite being from two different organisms, the structures obtained are very similar. Interestingly, the same portion of the proteins was stabilized after proteolysis treatment, and the overall structural elements are conserved.

\section{Rpf2 is a $5 S$ rRNA-specific RNA-binding protein}

The Brix domain proteins have been suggested to bind RNA, but their cognate RNA-binding sites have not been determined. The electrostatic potential mapped to the surface of the Rpf2-Rrs1 complex shows an extended basic surface along one side of the complex, principally centered within the Rpf2 protein that encompasses the $\alpha_{1}$ and $\alpha_{2}$ helices; the $\beta_{1}-\alpha_{1}, \beta_{3}-\beta_{4}$, and $\beta_{9}-\beta_{10}$ loops; and the $\beta_{5}-\beta_{6}$ linker between the two domains (Supplemental Fig. S2). This basic patch is likely the RNA-binding surface of Rpf2 and corresponds, on the first BID, to the 

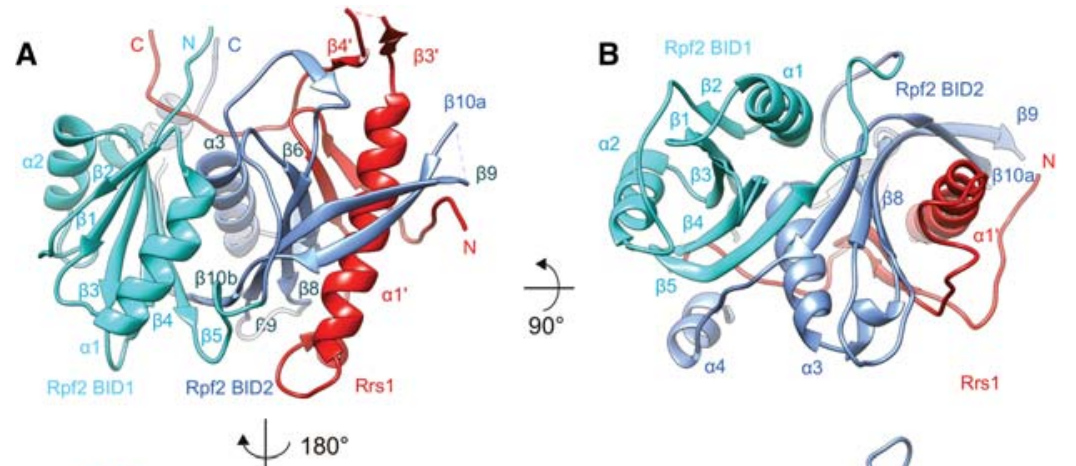

Figure 1. Structure of the Rpf2-Rrs1 complex. $(A-C)$ Ribbon representation of three orthogonal views of the Rpf2-Rrs1 complex. The Brix internal duplicated (BID) domains are represented in light and dark blue, and Rrs1 is shown in red. $(D)$ Superposition of the two Rpf2 BID domains shows that Rrs1 completes the structural elements in the second BID domain.

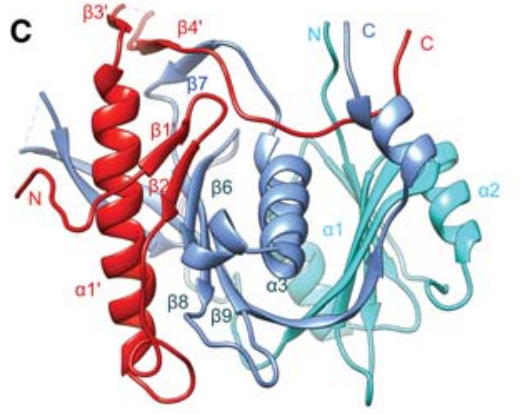

D

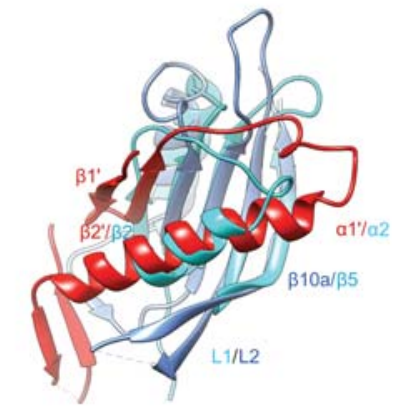

RNA binding surface of the homologous aaRS domain (Ng et al. 2005).

To identify Rpf2 and Rrs1 substrates in the cell, we performed genome-wide in vivo identification of the RNA-binding sites of Rpf2 and Rrs1 using the cross-linking and cDNA (CRAC) analysis methodology. Briefly, HTP-tagged Rpf2 or Rrs1 was cross-linked to RNA using UV irradiation, the protein-bound RNA was purified using denaturating conditions using the protein affinity tag and trimmed to the region protected by the protein using a cocktail of RNAses, cDNAs were generated, and the sequences were revealed by high-throughput sequencing (Granneman et al. 2009). During the process, the crosslinked RNAs were labeled with ${ }^{32} \mathrm{P}$ and analyzed by autoradiography. No enrichment for RNAs associated with Rrs1 was seen compared with the control. The majority of RNA fragments bound to Rpf2 correspond to the 5S RNA, as was expected, since Rpf2 is involved in 5S RNP recruitment into the ribosome (Fig. $2 \mathrm{~A}, \mathrm{~B}$ ). In addition to the 5S rRNA fragments, sequences corresponding to two neighboring regions of 25S rRNA were found bound to Rpf2 (Fig. 2C,D). Interestingly, these two regions flank helix 84-the binding site of both Rpl5 and Rpl11 and the main docking site for the 5S RNP in the pre-60S subunit.

We next set out to confirm the interaction of the recombinant Rpf2-Rrs1 complex with the 5S RNA in vitro. The 5S RNA is composed of a three-way junction containing five helical regions (I-V) and five loops (A-E) with coaxial packing of helix I onto helix II (Fig. 2C). As these types of structures can be hard to fold in vitro, we purified the 5S RNA from yeast to obtain RNA samples containing both post-transcriptional modifications and native-like structures (as evidenced form SAXS) (data not shown). The interaction of the Rpf2-Rrs1 complex with the 5S
rRNA was performed by both electrophoretic mobility shift assays (EMSAs; using radioactive-labeled RNA to determine the strength of the interaction) and circular dichroism (CD) spectroscopy to assess the conformational changes in RNA and protein components upon complex formation. We found that the Rpf2-Rrs1 complex efficiently bound to the $5 \mathrm{~S}$ rRNA with a $K_{\mathrm{d}}$ of $\sim 57 \mathrm{nM}$ (Fig. $3 \mathrm{~A}, \mathrm{~B})$, and $\mathrm{CD}$ spectroscopy showed that the interaction involves a structural rearrangement of the RNA (Fig. $3 \mathrm{C})$. In agreement with the in vivo data, no change in CD spectra was observed when Rrs1 alone was used (Supplemental Fig. S3C), indicating that Rrs1 does not contact this RNA directly. Rpf2 alone is very unstable but was still able to induce a small change in the RNA CD spectra (Supplemental Fig. S3B). We conclude that the contacts to the 5S rRNA principally involve Rpf2 and that, at least in vitro, Rpf2 is stabilized by the presence of Rrs1.

\section{Assembly of the Rpf2-Rrs1 complex onto the 5S rRNA}

Since the Rpf2-Rrs1 complex can interact with the 5S rRNA in vitro, we performed structural studies using SAXS to study the assembly of the complex in solution (data collection and modeling statistics are shown in Table 2). We first recorded SAXS data for both the full-length and the proteolyzed Rpf2-Rrs1 complex. The data clearly show that the proteolyzed complex is globular, and modeling confirms that the solution structure is the same structure as in the crystal (Fig. 4A). Analysis of the full-length complex revealed that the C-terminal regions of Rpf2 and Rrs1 form extended and unstructured extensions that protrude away from the structural core (data not shown). Because of the difficulty in modeling a protein-RNA complex with these unstructured regions, we performed EMSA 
Madru et al.
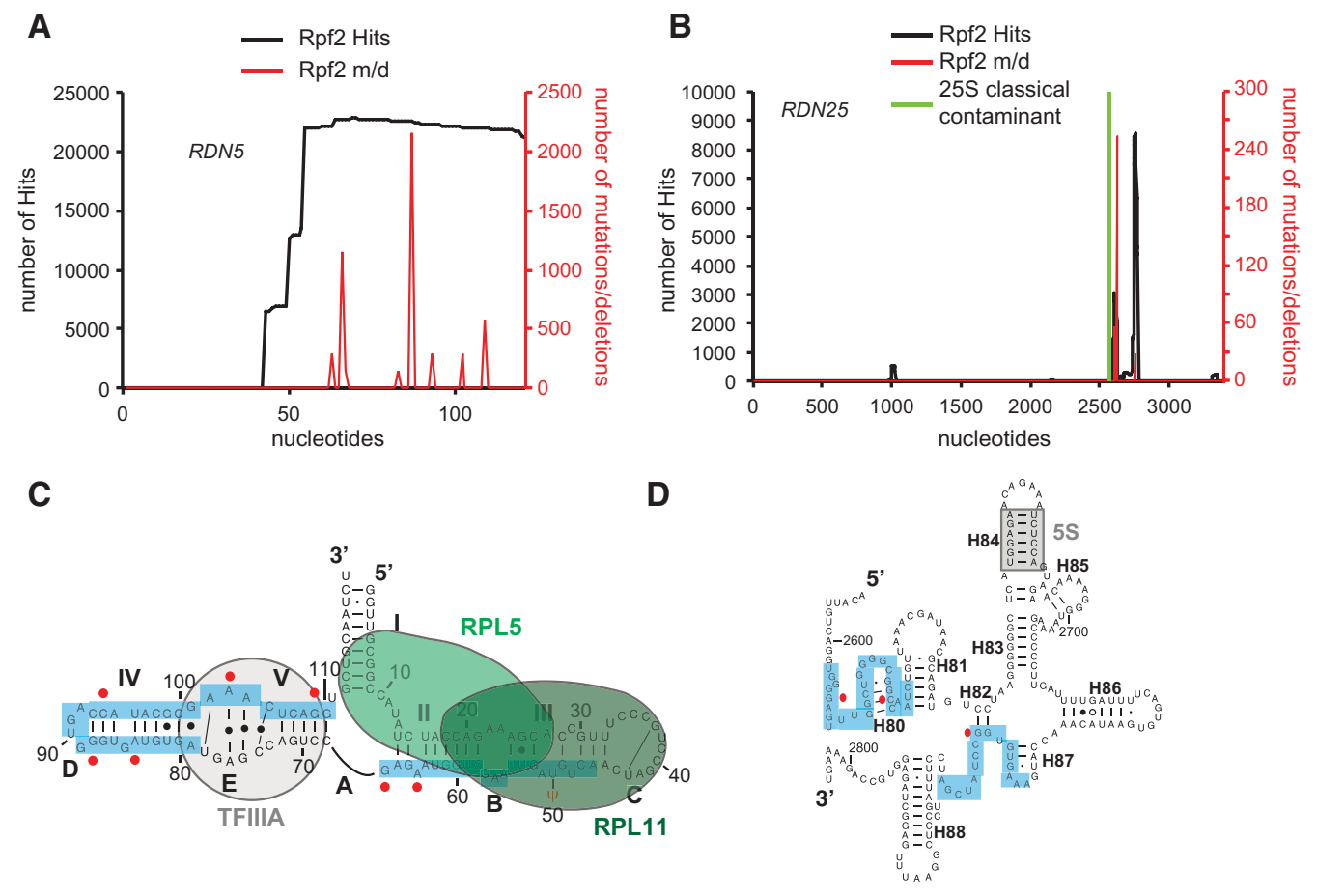

Figure 2. In vivo RNA-binding sites of Rpf2. $(A, B)$ RNAs in Rpf2-HTP cells were UV cross-linked in cells growing in culture medium, trimmed and ligated to linkers, amplified by RT-PCR, and sequenced with an ionTorrent. Sequences were aligned with main hits to the 5S rRNA (nucleotides 1-120) (A) and the 25S rRNA (nucleotides 1-3396) (B). The frequency of recovery (hits per 100,000 mapped reads) is plotted for each individual nucleotide (shown in black). The locations of mutations/deletions that are likely due to RNA cross-linking to the residue are shown in red. The location of a classical contaminant sequence found in the 3' end of the 25S rRNA (recovered with the "no tag" control experiment) is represented by a green bar. (C) Secondary structure of 5S RNA in yeast. The binding sites recovered for Rpf2HTP are indicated on the sequence (blue). Mutated nucleotides that indicate a direct cross-link are indicated by red dots alongside the sequence. Known binding sites for 5S-binding protein TFIIIA, Rpl5, and Rpl11 are indicated as gray, light-green, and dark-green circles, respectively. $(D)$ Secondary structure of the 25S RNA in yeast. The binding sites recovered for Rpf2-HTP are indicated on the sequence (blue). Mutated nucleotides are indicated by red dots alongside the sequence. Transient interaction between $5 \mathrm{~S}$ and $25 \mathrm{~S}$ in pre-60S particle is indicated as a gray square (Leidig et al. 2014).

using the trypsin proteolyzed samples that we used for the crystallization of the Rpf2-Rrs1 complex to determine whether it could be used for structural studies using RNA. Surprisingly, we found that while the proteolyzed sample still binds 5S RNA, it does so with eightfold less affinity compared with the complex containing the fulllength proteins (Fig. 3A,B). The conformational changes in the RNA observed by CD were also less pronounced with the proteolyzed sample (Fig. 3D). Since Rrs1 does not bind RNA, we attribute the higher affinity of the fulllength complex to the $\mathrm{C}$ terminus of Rpf2. These residues are not part of the consensus core Brix domain but are conserved in Rpf2 homologs. We conclude that in our in vitro assays, the nonconserved extensions of Rpf2 and Rrs1 likely refold when bound to the RNA and contribute to the binding affinity.

We further characterized the 5S rRNA-Rpf2-Rrs1 complex interaction using the proteolyzed Rpf2-Rrs1 complex and yeast 5S rRNA. Interestingly, the SAXSderived molecular envelope of the free 5S RNA clearly shows an unstacking of the RNA helices compared with the ribosome-bound structure (Fig. 4C). We interpreted and modeled the extended conformation of the RNA as the unbending and unstacking of helices I, II, and III in the absence of the Rpl11 and Rpl5 proteins. In the 5S rRNA-Rpf2-Rrs1 complex, inspection of the molecular envelopes for the RNA and protein phases revealed that the RNA adopts an extended conformation and that the protein complex binds within the first half of the RNA length around 5S RNA helix I (Fig. 4C). The modeling of the complex was performed using the ribosome-bound Rps2-Rrs1 structure (see the next section).

\section{Structure of the preribosome-bound Rpf2-Rrs1 complex}

Since the Rpf2-Rrs1 complex recruits the 5S RNP to the early preribosome complexes and is still present in late pre-60S particles, we reasoned that it should be present in the cryo-EM structures of Tap-Alb1-purified pre-60S particles (Leidig et al. 2014). Indeed, the presence of Rpf2 in these preribosomes was confirmed by mass spectrometry, and Rrs1 was probably not identified because of overlap with ribosomal protein bands. These particles contain $\sim 20$ ribosomal assembly factors and the $\mathrm{CP} / 5 \mathrm{~S}$ RNP rotated $180^{\circ}$ in respect to its final position in mature ribosomes (Supplemental Fig. S5; Leidig et al. 2014). We identified an 
A

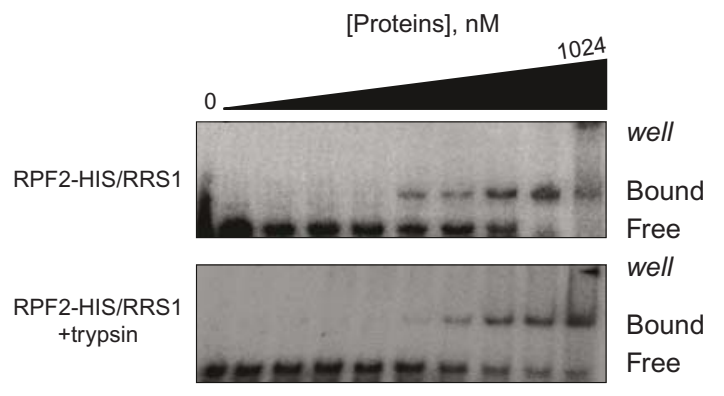

B

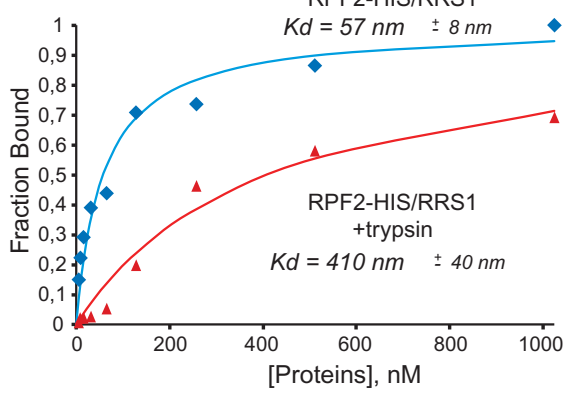

C
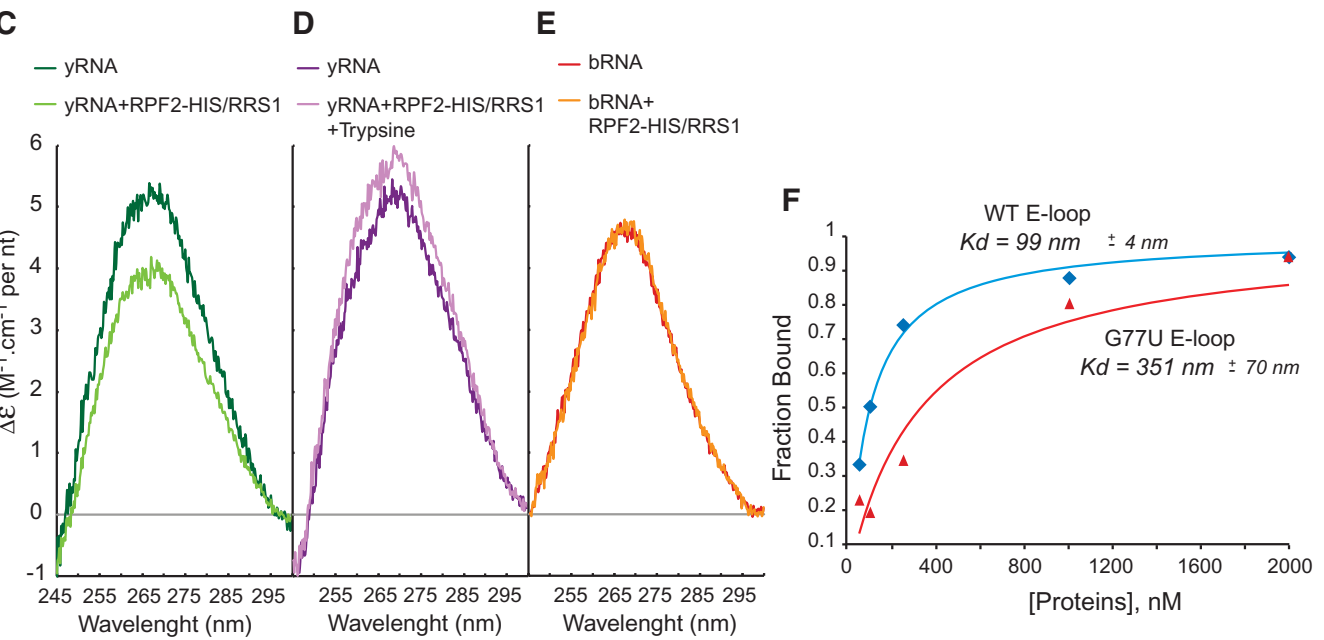

Figure 3. In vitro interaction of the Rpf2-Rrs1 complex with $5 \mathrm{~S}$ rRNA. (A) EMSA of the $5 \mathrm{~S}$ rRNA. $5{ }^{\prime}-{ }^{32} \mathrm{P}-1 \mathrm{labeled} 5 \mathrm{~S}$ rRNA was bound with $0,4,8,16,32,64,128,256,512$, and $1024 \mathrm{nM}$ indicated proteins. (B) Fractions of bound 5S rRNA for each protein concentration were quantified using PhosphoImager and plotted for the Rpf2/Rrs1 complex before (blue diamonds) or after (red triangles) $1 \mathrm{~h}$ of trypsin proteolysis. The theoretical curves are represented for the Rpf2/Rrs1 complex before (blue) and after (red) trypsin treatment. (C-E) CD analysis of the RNA conformational changes upon Rpf2/Rrs1 binding. (C) CD spectra of the yeast 5S rRNA (yRNA) obtained when the protein complex Rpf2/Rrs1 and the yRNA are present in two separate cuvette compartments (dark green) or after mixing the two compartments (light green). $(D)$ The same experiment as in $C$ but with the protein complex Rpf2/Rrs1 after trypsin treatment. Spectrum were recorded before (dark purple) and after (light purple) mixing proteins and yRNA. (E) The same experiment as in $C$ with bacterial 5S rRNA (bRNA) and the complex Rpf2/Rrs1 before (red) or after (orange) mixing the two compartments. (F) Filter-binding assay of the 5S rRNA E loop to the RPF2/RRS1 complex. The fluorescently labeled E loop of wild type or the G77U mutant was bound with 0, 25, 50, 100, 250, 1000, and $2000 \mathrm{nM}$ protein complex. Fractions of the bound E loop of wild type or the G77U mutant of the 5S rRNA for each protein concentration were quantified using odyssey (Li-COR) and are plotted for the wild-type E loop (blue diamonds) and G77U mutant (red triangles). The theoretical curves are represented for the wild type(blue) and G77U mutant (red).

unattributed density in the pre-60S structure contacting the 5S RNA helices I and V (Fig. 5A) in a region compatible with both the CRAC and SAXS data. We were able to fit the Rpf2-Rrs1 complex into this density (Fig. 5B). We then refined the structures of the neighboring molecules against the cryo-EM density, which provided us with a molecular model of Rpf2-Rrs1 in complex with the $5 \mathrm{~S}$ rRNA, ribosomal proteins, and preribosomal assembly factors within the pre-60S ribosome (Fig. 5B,C). The high resolution obtained in these cryo-EM studies 18.7 A) gives us a model of the Rpf2-Rrs1-preribosome structure in which the overall binding interfaces are unambiguously defined, but the detailed interaction at the residue level will require higher-resolution structures.

In this model, the Rpf2-Rrs1 complex contacts the $5 \mathrm{~S}$ rRNA at the junction of the helices I and IV (Fig. 5B), a re- gion distinct from the Rpl5- and Rpl11-binding regions (Figs. 2C, 5B). The structure shows that the four proteins Rpf2, Rrs1, Rpl5, and Rpl11 can coexist in the same complex with 5S RNA. Furthermore, in this complex, Rpl5 and Rpl11 are in the same conformation /relative to the 5S rRNA) as found in mature ribosomes. A model of the ribosome-bound 5S-Rpf2-Rrs1 complex was used in refinement against SAXS data, and we found a good fit to the scattering data and in the molecular envelope with a conformation in which the Rpf2-Rrs1 complex interaction is conserved, and helices II and III form an extended helix (Fig. 4D).

In summary, the preribosome-bound and solution structure of the 5S-Rpf2-Rrs1 complex shows that Rpf2-Rrs1 can bind to the 5S rRNA in the absence of Rpl5 and/ or Rpll1 and in the same overall conformation as the 
Table 2. SAXS data collection and modelling statistics

\begin{tabular}{|c|c|c|c|}
\hline & 5S RNA & Rpf2-Rrs1 trypsinized & 5S-Rpf2-Rrs1 trypsinized \\
\hline \multicolumn{4}{|l|}{ Data collection parameters } \\
\hline Instrument & SWING & BM29 & BM29 \\
\hline Beam geometry & $0.4 \mathrm{~mm} \times 0.1 \mathrm{~mm}$ & $0.5 \mathrm{~mm} \times 0.5 \mathrm{~mm}$ & $0.5 \mathrm{~mm} \times 0.5 \mathrm{~mm}$ \\
\hline Wavelength & $1.03 \AA$ & $1.00 \AA$ & $1.0 \AA$ \\
\hline$q$ range & $0.007-0.5 \AA^{-1}$ & $0.0025-0.5 \AA^{-1}$ & $0.0025-0.5 \AA^{-1}$ \\
\hline Exposure time/nb frames & $1 \mathrm{sec} / 100$ & $1 \mathrm{sec} / 10$ & $1 \mathrm{sec} / 10$ \\
\hline Concentration range & $10 \mathrm{mg} / \mathrm{mL}$ & $5-25 \mathrm{mg} / \mathrm{mL}$ & $5-25 \mathrm{mg} / \mathrm{mL}$ \\
\hline Temperature & 288 & 288 & 288 \\
\hline \multicolumn{4}{|l|}{ Structural parameters } \\
\hline $\mathrm{I}(0)[$ from $\mathrm{P}(\mathrm{r})]$ & $0.02 \mathrm{~cm}^{-1}$ & $0.06 \mathrm{~cm}^{-1}$ & $0.17 \mathrm{~cm}^{-1}$ \\
\hline $\operatorname{Rg}[$ from $\mathrm{P}(\mathrm{r})]$ & $37.8 \AA$ & $22.49 \AA$ & $38.06 \AA$ \\
\hline $\mathrm{I}(0)$ (from Guinier) & $0.02 \mathrm{~cm}^{-1}$ & $0.06 \mathrm{~cm}^{-1}$ & $0.17 \mathrm{~cm}^{-1}$ \\
\hline $\mathrm{Rg}$ (from Guinier) & $35.2 \AA \pm 2.3 \AA$ & $22.89 \AA \pm 1.23 \AA$ & $36.84 \AA \pm 0.83 \AA$ \\
\hline$D_{\max }$ & $122.3 \AA$ & $71.5 \AA$ & $128.9 \AA$ \\
\hline Porod estimate & $62,902 \AA^{3}$ & $63,190 \AA^{3}$ & $104,848 \AA^{3}$ \\
\hline \multicolumn{4}{|l|}{ Molecular mass determination } \\
\hline Partial specific volume & $0.54 \mathrm{~cm}^{3} / \mathrm{g}$ & $0.745 \mathrm{~cm}^{3} / \mathrm{g}$ & $0.639 \mathrm{~cm}^{3} / \mathrm{g}$ \\
\hline Contrast $\left(\Delta \rho \times 10^{10} \mathrm{~cm}^{-2}\right)$ & 6.283 & 2.736 & 4.510 \\
\hline Molecular mass $M_{\mathrm{r}}[$ from $\mathrm{I}(0)]$ & 39,314 & 39,494 & 75,530 \\
\hline Calculated monomeric $M_{\mathrm{r}}$ from sequence & 39,155 & 37,558 & 76,713 \\
\hline \multicolumn{4}{|l|}{ Data processing } \\
\hline Primary data reduction & FOXTROT & EDNA-SAS pipeline & EDNA-SAS pipeline \\
\hline Data processing & PRIMUS & PRIMUS & PRIMUS \\
\hline $\mathrm{Ab}$ initio analysis & DAMMIF & DAMMIF & MONSA \\
\hline Number of models & 50 & 50 & 20 \\
\hline Model $\chi^{2}$ & $2.196 \pm 0.020$ & $0.855 \pm 0.050$ & $2.38 \pm 0.068$ \\
\hline Validation and averaging & DAMAVER & DAMAVER & DAMAVER \\
\hline Normalized spatial discrepancies & $0.786 \pm 0.145$ & $0.978 \pm 0.169$ & $0.629 \pm 0.112$ \\
\hline Rigid body modeling & MC-SYM & DADIMODO & SASREF \\
\hline Computation of model intensities & CRYSOL & CRYSOL & CRYSOL \\
\hline Model $\chi^{2}$ & 1.866 & 1.289 & 1.677 \\
\hline
\end{tabular}

ribosome-bound conformation for helices I and V in the 5S rRNA but that helices II and III require the interaction with Rpl5 and Rpl11 in order to attain their mature conformation. Our data are consistent with the model in which the 5S RNP-Rpf2-Rrs1 complex is incorporated as an independent structural module in preribosomes.

\section{Rpf2 recognizes a eukaryote-specific E loop} in the $5 S$ rRNA

Close analysis of the preribosome-bound Rpf2-Rrs1 complex reveals that the main contact to 5S RNA is with the E loop between helices IV and V (Fig. 2C). While all 5S rRNA species contain an E loop, the sequence is significantly different between eukaryotes and prokaryotes. The E loop forms a G-bulged cross-strand stack structure consisting of three stacked non-Watson-Crick base pairs, a bulgedout guanine (G77) that forms a base triple with A78 and U102, and two cross-strand purine stacking interactions. Loop E is therefore a well-folded and rigid structure (Lee et al. 2006) that provides structural features that could constitute a specific protein-binding site: an unusual backbone geometry, a widened major groove, unique hydrogenbonding possibilities to the non-Watson-Crick base pairs, and a bulged-out guanine. To confirm that the E loop is important for the specific recognition of the 5S RNA by
Rpf2, we performed in vitro binding assays with bacterial-purified 5S rRNA (Fig. 3E), which contains the same overall structure as the eukaryote rRNA but a different $\mathrm{E}$ loop. No interaction between Rpf2-Rrs1 and bacterial 5S rRNA was observed by gel shift assays (data not shown) or CD spectra (Fig. 3E), indicating that the eukaryotic E loop is the specific RNA-binding element for Rpf2. To confirm this result, we analyzed the interaction between the Rpf2-Rrs1 complex and a labeled RNA probe containing only the E loop and its flanking helices (Supplemental Fig. S3E) using a filter-binding assay. The Rpf2/Rrs1 complex was able to bind this construct with a $K_{\mathrm{d}}$ of $99 \mathrm{nM}$, and the substitution of the looped-out guanine residue (G77) (Fig. 6A) for a uridine leads to a threefold decrease of the binding affinity (Fig. 3F; Supplemental Fig. S3D).

Rpf2 contacts the 5S rRNA along the previously observed conserved basic patch (Supplemental Fig. S2). The contacts to loop $\mathrm{E}$ in the major groove involve the $\beta_{1}-\alpha_{1}$ and $\beta_{3}-\beta_{4}$ loops. The $\beta_{2}-\alpha_{2}$ loop also contacts the loop E $5^{\prime}$ strand backbone and the minor groove of helix IV. The $\beta_{3}-\beta_{4}$ loop contains conserved and charged amino acids that bind the RNA backbone on both sides of the loop $\mathrm{E}$ and certainly contribute to the specific recognition of the loop E structure. It also places residues of the $\beta_{3}-\beta_{4}$ loop within hydrogen-bonding distance of the bulged guanine (Fig. 6A). All of the protein interactions with the 
A
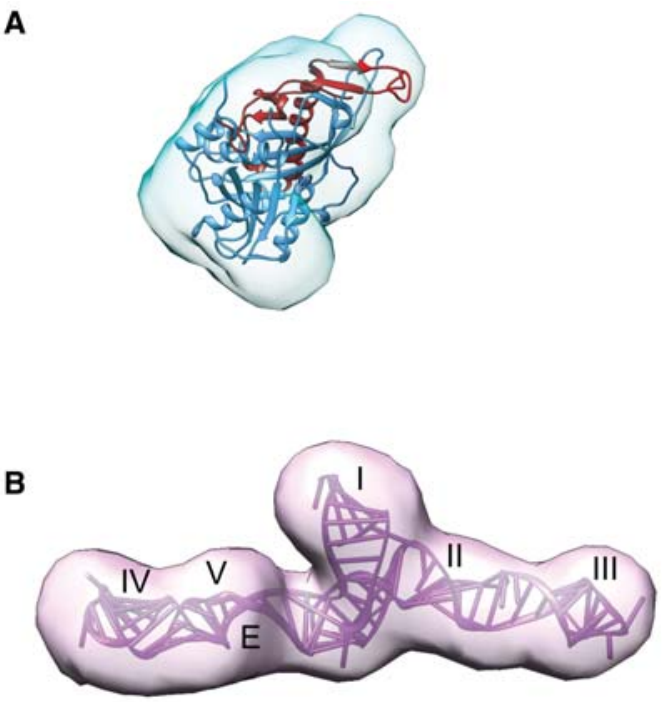

C

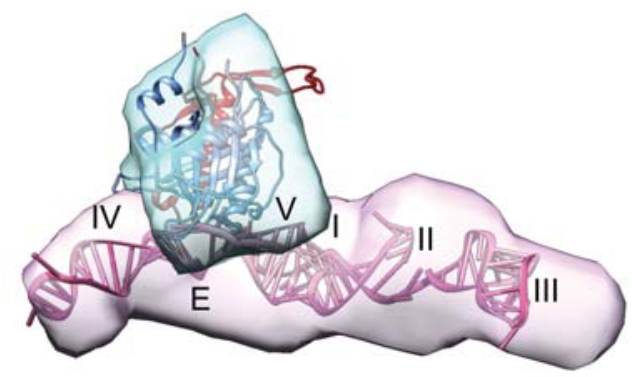

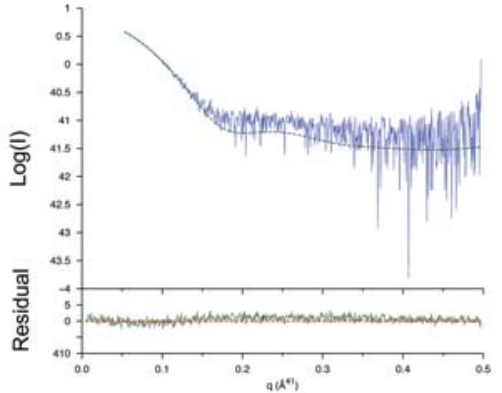
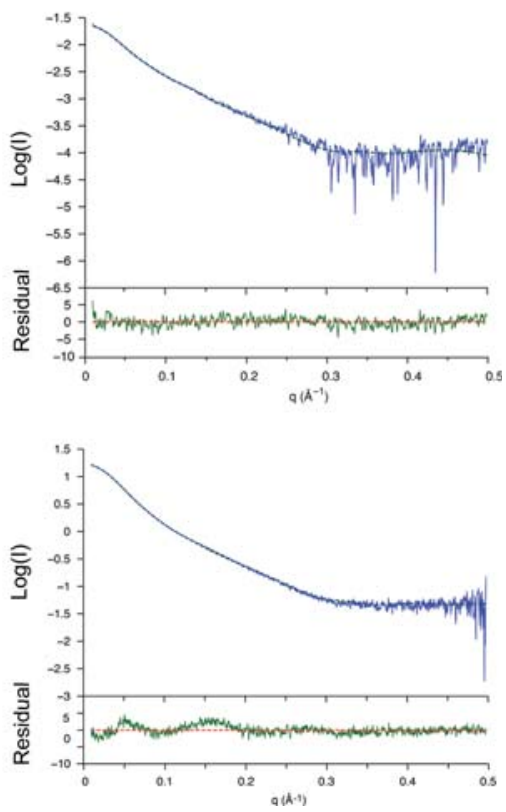

Figure 4. SAXS-derived solution structures of the Rpf2 subcomplexes. Solution structure model of the Rpf2-Rrs1 complex in the proteolyzed state $\left(\chi^{2}=1.289\right)(A)$, the full-length Rpf2-Rrs1 complex $\left(\chi^{2}=1.701\right)(B)$, the free 5S RNA $\left(\chi^{2}=1.866\right)(C)$, and the Rpf2-Rrs1-5S complex with proteolyzed proteins $\left(\chi^{2}=1.677\right)$. The structures are superposed to a representative envelope calculated by DAMMIN $(A, B)$ or MONSA $(C)$. The proteins and RNA are represented in the same orientation. The corresponding calculated X-ray scattering curves (dashed green) superposed to the experimental scattering curves (blue) are shown in the right panel. The locations of interesting $5 \mathrm{~S}$ structural elements are indicated by their names to refer to Figure 2C.

E loop lie within the first BID domain of Rpf2. Superposition of the Rfp2-5S RNA and aaRS-synthetase-tRNA complex shows that the proteins recognize very different RNA substrates with different regions of the protein domain: Binding of Rpf2 is primarily to the E-loop major groove, while aaRS binds the anti-codon loop of a stemloop structure (Supplemental Fig. S4B). The only common RNA-binding element maps to the $\beta_{2}-\alpha_{2}$ loop contacting the 3' strand of the loop E in the Rpf2-5S complex.

Loop E-like structures are known to mediate specific protein-RNA interactions, such as the sarcin-ricin loop (SRL) of the 25S rRNA with ricin or EF-G and, more interestingly, TFIIIA to the 5S rRNA E loop (Lu et al. 2003). Superposition of the structures of Rpf2 and TFIIIA bound to the $5 \mathrm{~S}$ rRNA shows that although the two proteins use different strategies to bind the 5S loop E, the binding surfaces of the two proteins overlap on the RNA. This indicates that binding of TFIIIA and Rpf2 to the 5S rRNA is mutually exclusive (Supplemental Fig. S4A). It has also been reported that Rpl5 displaces TFIIIA on the $5 \mathrm{~S}$ rRNA due to overlap of their binding sites. These mutually exclusive interactions might ensure the proper sequential interaction of proteins with the 5S rRNA along the maturation pathway. Indeed, TFIIIA could prevent Rpf2 from binding the naked 5S rRNA early in the pathway before the TFIIIA/Rp15 exchange.

The Rpf2 complex docks the $5 S$ RNP into the pre-60S particles using a network of RNA and protein interactions

The structure of the Rpf2-Rrs1 complex bound to the pre$60 \mathrm{~S}$ defines its interaction with the 5S rRNA but also suggests additional contacts to the 25S rRNA and neighboring proteins. Analysis of the CRAC data revealed that, in addition to the $5 \mathrm{~S}$ rRNA, Rpf2 contacts the $25 \mathrm{~S}$ rRNA around helices 80 and 87 . No contacts between the conserved Brix domain structural core and the 25S RNA are 
A

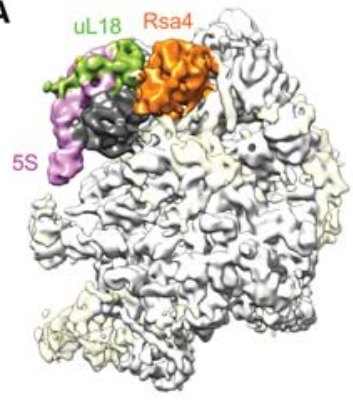

B

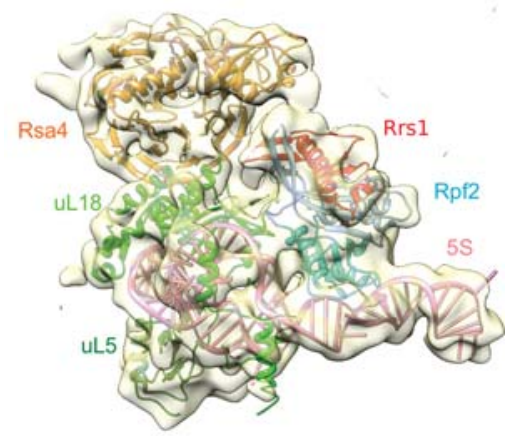

C

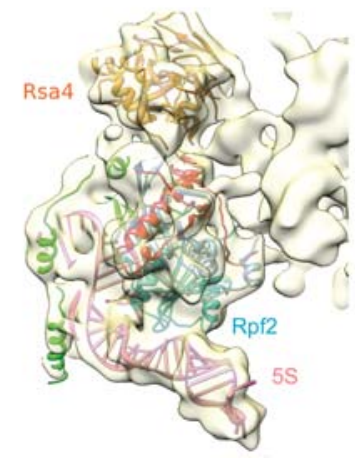

Figure 5. Electron microscopy structure of pre-60S bound Rpf2Rrs1. (A) Cryo-EM structure of the Alb1-TAP purified pre-60S particles (emd 2528) (Leidig et al. 2014). The unidentified density in contact with $5 \mathrm{~S}$ (pink) and Rsa4 (orange) is shown in dark gray. ( $B$, C) Orthogonal views of the Rpf2-Rrs1 crystal structure fit in the cryo-EM density. No optimization of the Rpf2-Rrs1 structure was performed.

observable in the pre-60S complex in this region. However, the position of the RNA regions found is compatible with an interaction with the "unstructured" C-terminal region of Rpf2, which was not visible in the crystal structure. Unidentified electron density links the last observed residues of Rpf 2 with the $25 \mathrm{~S}$ rRNA, suggesting that the conserved region following the canonical Brix domain binds this region of the rRNA (Fig. 6B). In the in vitro binding assays, we showed that this region has RNA-binding capabilities because it improves binding of Rpf2 to the 5S rRNA (Fig. 3A-D). We propose that the Rpf2 C-terminal extension contributes to 5S RNP assembly in preribosomes by binding an exposed region of the 25S RNA in proximity to the 5 S-binding site.
The importance of the C-terminal domain (CTD) of Rpf2 has been tested by expressing either PTH-tagged versions of full-length (FL) Rpf2, the N-terminal domain (NTD) 1-252 of Rpf2, or the CTD 253-344 of Rpf2 in the presence or absence of the endogenous protein in yeast (Supplemental Fig. S6). As expected, only the full-length protein was able to complement the absence of the endogenous copy (Supplemental Fig. S6A). Interestingly, expression of the NTD mutant exerts a clear dominantnegative effect on growth (Supplemental Fig. S6A). This result supports a model in which the NTD competes with the endogenous copy for 5S RNP binding but fails to progress further in the maturation pathway. This could be due to the impossibility of recruiting the 5S RNP to the ribosome or the inhibition of a subsequent step mediated by the Rpf2 $\mathrm{C}$ terminus. In order to distinguish between these two possibilities, we affinity-purified Rpf2FL, Rpf2-NTD, and Rpf2-CTD and analyzed the bound RNA. We found a 1.6-fold decrease in the ratio of bound $5.8 \mathrm{~S}$ versus 5S RNA between Rpf2-FL and Rpf2-NTD, indicating that the recruitment of $\mathrm{Rpf} 2$ in the ribosome is affected in the absence of Rpf2-CTD (Supplemental Fig. S6C,D). No significant amount of RNA was retrieved with Rpf2-CTD alone, indicating that this region is not

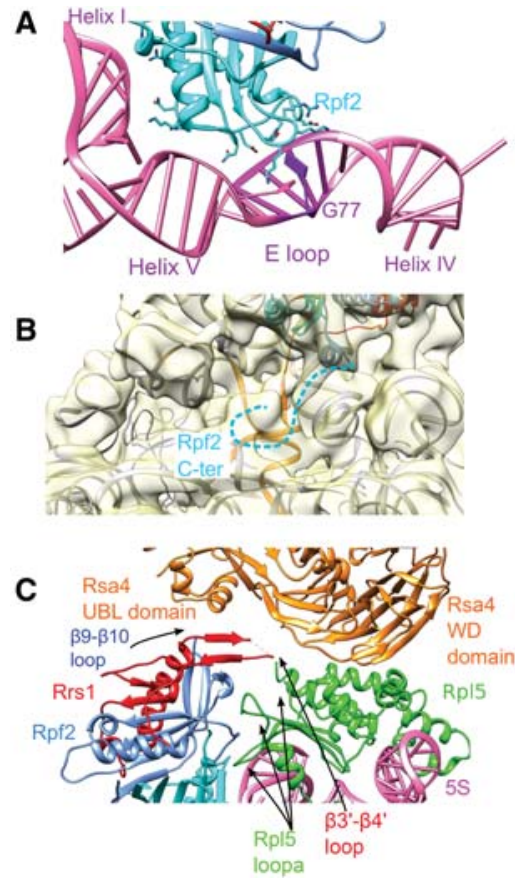

Figure 6. RNA and protein contacts in the preribosomes. $(A)$ Rpf2 binds the 5S RNA E loop. The 5S RNA and the Rpf2-Rrs1 complex were fitted simultaneously in the electron density with flexible molecular dynamics using MdFF. The E loop is colored in purple, and the looped-out guanine is depicted in a solid cartoon. $(B)$ Rpf2 contacts to the 25S rRNA. The predicted C-terminal extension of Rpf2, not visible in the crystal structure, is shown by a dashed line. The rRNA sequence identified by CRAC is colored in orange. $(C)$ Protein-protein interaction with the Rpf2-Rrs1 complex in the preribosome. 
sufficient for binding preribosomal particles but, in synergy with the Rpf2-NTD, helps the recruitment of the 5S RNP.

In the pre-60S-bound complex, Rpf2 and Rrs1 are in close proximity to the ribosomal protein Rpl5 and the nonribosomal protein Rsa4. Rpl5/uL18 has already been shown to interact with Rsa4 (Leidig et al. 2014), and interactions have been observed between Rp15, Rpl11, Rpf2, and Rrs1 (Zhang et al. 2007). The structure of the ribosome-bound Rpf 2 complex shows that the Rpf $2 / \mathrm{Rp} 15$ interaction involves the Rpl5 eukaryote-specific loops that are also involved in Rsa4 binding (Leidig et al. 2014). This suggests that Rpf2 specifically binds to the $5 \mathrm{~S}$ rRNA/Rpl5 complex for integration in the preribosomes. In addition, Rrs 1 and Rpf 2 interact with not only Rpl5 but also the Rsa4 assembly factor. In the pre-60S structure, the Rrs1 $\beta_{3^{\prime}}-\beta_{4^{\prime}}$ and Rpf $2 \beta_{9}-\beta_{10}$ loops, which are not visible in the crystallographic electron density of the Rpf2-Rrs1 complex, are in proximity to the WD repeat domain and the ubiquitin-like (UBL) domain of Rsa4 (Fig. 6C). These interactions could participate in the network of protein-protein and protein-RNA interactions that anchor the Rpf2-Rrs1-5S RNP complex in the preribosomes containing the Rsa4 assembly factor and the correct local structure of the $25 \mathrm{~S}$ rRNA.

\section{Discussion}

\section{Brix domain proteins serve as structural hubs} that bind both RNA and protein

The structure of the Rpf2-Rrs1 complex provides us with a model for the function of Brix domain proteins. The first striking observation is the unexpected nature of the interaction between the two proteins. Rrs1 forms a tight complex with Rpf2 and completes the Rpf2 structure. The absence of a free pool of Bxdc1 and hRrs1 in vivo (Sloan et al. 2013), the poor solubility and stability of Rpf2 in vitro (this study), and the instability of Rpf2 in vivo upon depletion of Rrs1 (Zhang et al. 2007) suggest that the proteins always exist in a complex. It is tempting to speculate that other members of the Brix domain family use the same interaction surface to bind Rrsl-like partner proteins. The Rpf2 residues forming salt bridges and/or hydrogen bonds with Rrs1 are not strictly conserved in the Brix domain family, suggesting that Rrs1 does not bind other Brix domain proteins. However, conserved residues specific to each family lie along the Rrs1-interacting surface, suggesting that they bind other proteins, which could define a Brix domain-associated protein (BAP) family. Members of the Brix family have been shown to form specific complexes with other ribosome assembly factors: Imp4 with Imp3/Mpp10 and Brx1 with Ebp2. It remains to be determined whether these Brix domains use the same binding strategy as Rpf2.

The identification of the Rpf2-Rrs1 complex in the pre60S structure revealed how this complex binds RNA. All of the protein-RNA contacts are made by Rpf2 in both the Brix domain and the C-terminal extension. On the other hand, Rrs1 does not contact RNA; it faces the exte- rior of the 5S RNP and is available to interact with other proteins. The data presented here on Rpf 2 provide the first evidence that Brix domain proteins can bind specific RNA elements with high affinity. The binding site for Rpf2 in the 5S rRNA, the three-way junction, and loop E structure suggest that Brix domain proteins bind both double-helical and loop/bulge RNA structures and can therefore recognize complex RNA three-dimensional structures. The C-terminal extension also provides longrange RNA-binding capabilities to either recruit the complex to a specific loci or monitor the proper folding of distal RNA structures. In agreement with this hypothesis, the Brix domain of Imp4 is sufficient to bind the U3 snoRNA, but the full-length Imp4 is required to form the duplex between the U3 snoRNA and the pre-rRNA (Gérczei and Correll 2004).

From our data, we conclude that the Brix domain is a docking platform that mediates both RNA and protein contacts. Domain duplication in the Brix domain was followed by function specialization: The first domain provides RNA specificity (Fig. 6A), and the second serves as a protein-binding module (Fig. 6C). The function of Rpf2 is to bring together different regions of the preribosomes by acting as a structural hub for preribosomal proteins, rRNA, and ribosomal proteins. In the case of the Rpf2-Rrs1 complex, the question arises of why the Rpf2 Brix domain binds the Rrs1 BAP, which in turn provides binding specificity to Rsa4. An intriguing possibility is that the ancestral form of the Brix domain was able to bind multiple BAPs that acted as adapters for an RNA substrate structure resembling the $\mathrm{E}$ loop and protein interaction sites. In the course of evolution, these complexes specialized to form different Brix domain proteins having different RNA substrate specificities. This is in agreement with the observation that archaeal genomes contain only one Brix domain protein, yeasts contain half a dozen, and metazoan genomes code for $>10$ members of this family of protein. The differences in the number of Brix domain proteins between archaea, yeast, and metazoans correlate with the increasing complexity of ribosome biogenesis in these organisms. A speculative hypothesis is that, in eukaryotes, a single Brix domain protein could be addressed to different RNAs through protein-protein interactions using different BAPs. This would be compatible with the ribosome-independent roles of several ribosome assembly factors, including Rrs1 (Gambe et al. 2009), Brix protein Ssf1 homolog PeterPan (Bugner et al. 2011), and Imp4 (Furtado et al. 2007).

\section{The Rpf2-Rrs1-5S RNP complex acts as a structural probe for correct ribosome assembly}

The ribosome-bound structure of the Rpf2-Rrs1 complex not only defines it as a $5 \mathrm{~S}$ rRNA binding module but shows that Rpf2 and Rrs1 anchor the 5S rRNA and Rpl5 in a network of interactions with the Rsa 4 assembly factor and 25S RNA. This work has enabled us to assign possible function to Rpf2 and Rrs1 during 5S RNP incorporation into the preribosome (Schematic model in Fig. 7). Rpf2 


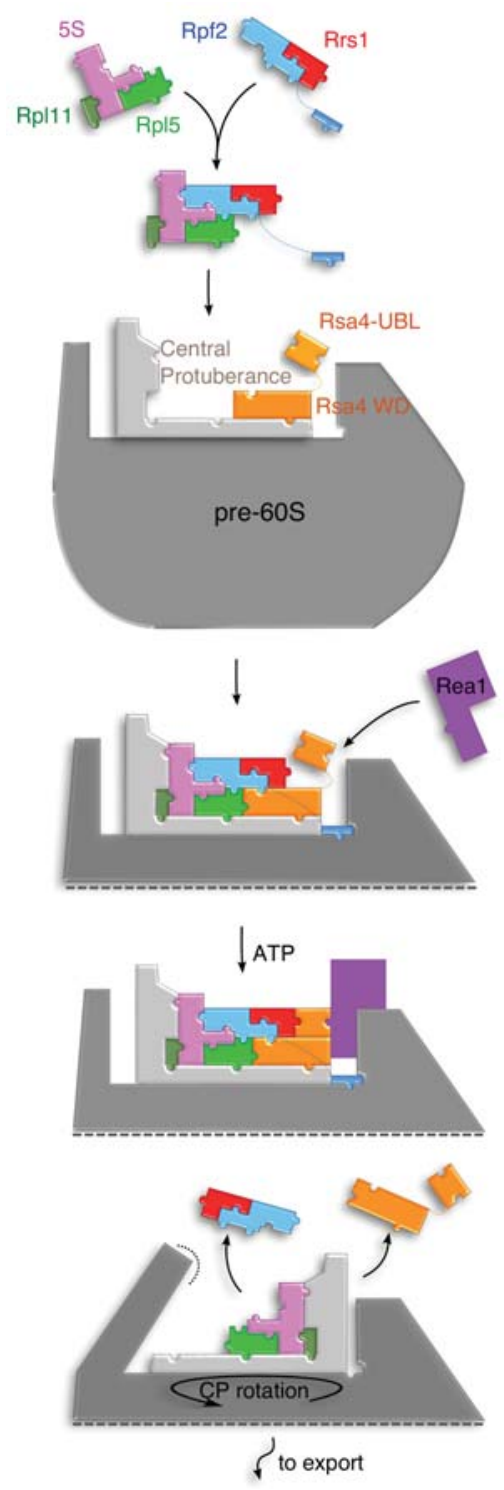

Figure 7. Jigsaw puzzle model for Rpf2/Rrs1 complex function in 5S RNP integration in preribosomes. Strong affinity of the Rpf2/Rrs1 complex for the 5S rRNA suggests that it recruits the free pool of 5 S RNP. In this complex, the 5S RNP can only assemble the preribosomes containing the correct conformation. The preassembled Rpf2/Rrs1 targets the 5S RNP onto pre-60S ribosomes using interactions between Rpf2 and the 25S rRNA and between Rpf2/Rrs1/Rpl5 and Rsa4. The Rsa4 UBL domain is positioned by Rrs1 to allow the interaction with Rea1, which recycles Rsa 4 and Rpf2/Rrs1 from the pre-60S particle and allows the $5 S$ RNP to adopt its final configuration state through a $180^{\circ}$ rotation of the CP.

specifically binds to the 5S rRNA/Rpl5 RNP and helps dock this complex onto the 25S RNA. The 5S assembly pathway prior to this step has been omitted in Figure 7, and it is not known whether Rpf2/Rrs1 can have a role in the assembly of Rpl5/Rpl11 on the 5S RNA. It is also possible that the import factor Syol is involved in chaperoning the assembly of Rpl11 on the H84 helix (Calviño et al. 2015). The Rpf2-binding surface on the 25S rRNA identified by CRAC is exposed only in the rotated state of the pre-60S CP and not in the mature 60S particles, which confirms that this state is indeed an on-pathway intermediate. Additional contacts to the Rsa4 factor by Rp15, Rpf2, and Rrs1 also ensure that 5S RNP is addressed to ribosomes with the rotated $\mathrm{CP}$. This interaction could provide selectivity for recruiting the 5S RNP only to the particles that have the proper conformation (Fig. 7). Indeed, because the 5S rRNA-Rpl5-Rpl11 complex has the same structure as mature ribosome-bound 5S RNP, it could very well associate with malformed preribosomal particles that have bypassed quality control mechanisms, for example, by the premature action of Real to rotate the CP before the 5S RNP and other factors have been assembled. However, since the 5S RNP-Rpf2-Rrs1 complex is not compatible with the position of the $5 \mathrm{~S}$ in the mature 60S (Supplemental Fig. S5), the association of Rpf2-Rrs1 to 5S RNP in the nucleolus would function in preventing the association with malformed preribosomes. The high affinity of Rpf2-Rrs1 to the 5S RNP and the requirement of Bxdc1/hRrs1 for nucleolar localization of the 5S RNP (Sloan et al. 2013) suggest that it binds the 5S RNP nucleolar pool to control and direct its incorporation in the correct preribosomes. We suggest that the interaction of the Rpf2-Rrs1 complex with the 5S RNP provides a quality control checkpoint by defining a building block that can interact with only specific preribosomal particles (Fig. 7).

It has been hypothesized that Rsa4 relays structural information at various regions of the pre-60S. It is thought that removal of this central "pin" by the Real AAA ATPase rips out the interacting proteins and leads to a major remodeling of the pre-60S particles by rotation of the $\mathrm{CP}$ (Baßler et al. 2014). It is not yet known what triggers the action of the Real ATPase. We suggest that the Rpf2-Rrs1 complex, positioned at the interface between Rsa4 and 5S rRNA, contributes to this major rearrangement. Indeed, The Rpf2-Rrs1 complex binds the UBL domain of Rsa4, which is involved in recruiting the Real ATPase (Ulbrich et al. 2009). In the Rsa4 crystal structure, this domain is found in different orientations with respect to the WD repeat domain (Leidig et al. 2014). Interaction with the Rfp2-Rrs1 complex could stabilize an orientation of the UBL domain, which offers an extended interaction surface for Real recruitment and activation. In this model, recruitment of the 5 S RNP by the Rpf2-Rrs1 complex would act to both select the correct preribosomes and enable the ribosome biogenesis to proceed to the next step by activation of Real.

Recent advance in the understanding of the Mdm2p53-ribosomal protein revealed that regulation of p53 is mediated by the 5 S RNP. The 5 S RNP appears to be an important target for anti-cancer and anti-ribosomopathy drugs. In addition, it was shown that depletion of either hRrs1 or Bxdc1 induces the p53 response. We therefore propose that targeting the Rpf2-Rrs1/5S rRNA interaction would both impair ribosome biogenesis and activate p53 by the Mdm2-p53-5S RNP pathway and could constitute a novel therapeutic target for cancer. 


\section{Materials and methods}

Cloning, expression, and purification

The ORFs of the RRS1 and RPF2 genes from Saccharomyces cerevisiae were synthesized commercially by Genscript Corp. and inserted into $\mathrm{pET} 21\left(\mathrm{a}^{+}\right)$(Novagen) as a pET21-Rpf2-Rrs1 polycistronic construct with an N-terminal 6xHis-tagged Rpf2 fusion protein. The expression and purification were essentially as described (Loc'h et al. 2014). Briefly, the proteins were expressed in the Rosetta 2DE3 strain from Escherichia coli (Invitrogen) at $37^{\circ} \mathrm{C}$ in LB medium (Sigma) supplemented with $100 \mu \mathrm{g} / \mathrm{mL}$ ampicillin and $25 \mu \mathrm{g} / \mathrm{mL}$ chloramphenicol until $\mathrm{OD}_{600}$ between 0.6 and 0.8 . Recombinant protein expression was induced by adding $1 \mathrm{mM}$ isopropyl- $\beta$-D-1-thiogalactopyranoside, incubating overnight at $20^{\circ} \mathrm{C}$, harvesting by centrifugation, and resuspending in buffer A $150 \mathrm{mM}$ Tris- $\mathrm{HCl}$ at $\mathrm{pH} 8,500 \mathrm{mM} \mathrm{NaCl}, 20 \mathrm{mM}$ imidazole) supplemented with complete EDTA-free protease inhibitors (Roche). Cells were lysed by sonication, and lysate was centrifuged at 20,000 rpm for $30 \mathrm{~min}$.

The clear lysate containing the Rrs1-Rpf2 6xHis-tagged complex was loaded onto a 5-mL HisTrap (GE Healthcare) connected to an ÄKTA pure (GE Healthcare). The Rrs1-Rpf2 6xHis-tagged complex was eluted with a linear gradient of imidazole (buffer B, $50 \mathrm{mM}$ Tris- $\mathrm{HCl}$ at $\mathrm{pH} \mathrm{8,500} \mathrm{mM} \mathrm{NaCl}, 500 \mathrm{mM}$ imidazole). Gel filtration was then performed on the eluted fractions containing protein complex using buffer $\mathrm{C}(50 \mathrm{mM}$ Tris- $\mathrm{HCl}$ at $\mathrm{pH} 8,150$ $\mathrm{mM} \mathrm{NaCl}$ ) on a Superdex 200 26/60 (GE Healthcare).

\section{Crystallization, data collection, and processing}

Crystallization trials were performed at $18^{\circ} \mathrm{C}$ using the hanging drop vapor diffusion technique in 1- $\mu \mathrm{L}$ drops (with a 1:1 protein: precipitant ratio) equilibrated against $500 \mu \mathrm{L}$ of reservoir solution. The Rrs1-Rpf2 His-tagged complex was first digested for $1 \mathrm{~h}$ at $30^{\circ} \mathrm{C}$ using a bovine trypsin solution at $1 / 1000$ ratio $(\mathrm{w} / \mathrm{w})$ and was used in crystallization trials without further purification. Crystals were obtained in $0.2 \mathrm{M} \mathrm{LiSO} 4,30 \%(\mathrm{w} / \mathrm{v})$ polyethylene glycol 4000, and $0.1 \mathrm{M}$ TrIs- $\mathrm{HCl}(\mathrm{pH} 8.5)$ with a complex solution at $15 \mathrm{mg} / \mathrm{mL}$ containing trypsin. Crystals were cryoprotected using successive soaking steps in increasing concentrations of ethylene glycol.

X-ray data were tested and optimized at the European Synchrotron Radiation Facility (ESRF) and collected at the Soleil synchrotron on beamlines Proxima1 and Proxima2. For phasing, crystals were soaked in a reservoir solution containing $10 \mu \mathrm{M}$ potassium tetrachloroplatinate $(\mathrm{PtCl} 4)$ or hexachloroplatinate $(\mathrm{PtCl})$, and data were collected at the absorption threshold of platinum (1.0716 ̊). Native and derivative data sets were indexed using XDS (Kabsch 2010) and Mosflm (Leslie and Powell 2007). The structure was solved by single isomorphous replacement with anomalous scattering using the $\mathrm{PtCl} 4$ derivative. Since native data sets were not isomorphous, the $\mathrm{PtCl} 6$ data set, which did not contain anomalous signal, was used as a native data set and phased with SHARP (Bricogne et al. 2003). Experimental phasing and molecular replacement were carried out with the Autosol and Phaser programs from Phenix (Adams et al. 2010). The initial rebuilding was carried out with Buccaneer from the CCP4 program suite (Collaborative Computational Project 1994) and subsequent rebuilding and refinement were carried out with COOT (Emsley and Cowtan 2004) and the Refine module from Phenix. Structures were fitted in the cryo-EM electron density (emdb 2528) using Chimera (Pettersen et al. 2004) and were refined using MdFF (Trabuco et al. 2008).

\section{Yeast strains}

The strains used are listed in Supplemental Table S1. For the CRAC approach, the genomic copies of Rpf2 and Rrs1 were C-ter- minally tagged (Longtine et al. 1998) for expression as a Rpf2His6-TEV-2ProteinA (HTP) and a Rrs1-HTP fusion in the

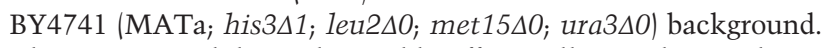
The HTP tags did not detectably affect cell growth. To obtain plasmids expressing PTH-tagged mutants of Rpf2, cDNAs corresponding to each mutant were amplified by PCR and cloned into pRS415-PTH via XmaI restrictions sites.

\section{Yeast RNA isolation}

The wild-type BY4741 strain from S. cerevisiae was grown at $25^{\circ}$ $\mathrm{C}$ in $1 \mathrm{~L}$ of YPD medium to an $\mathrm{OD}_{600}$ of 8 . The cell culture was then divided into six pots and harvested by centrifugation. Extracts were prepared from pellets resuspended in $1.5 \mathrm{~mL}$ of guanidinium thyocianate-phenol $\mathrm{mix}(1: 1[\mathrm{v} / \mathrm{v}])$ with $1.5 \mathrm{~mL}$ of zirconia beads and vortexed for $5 \mathrm{~min}$. Twelve microliters of guanidinium thyocianate-phenol $\mathrm{mix}(1: 1[\mathrm{v} / \mathrm{v}])$ was then added, and extracts were incubated for $10 \mathrm{~min}$ at $65^{\circ} \mathrm{C}$ and left for $10 \mathrm{~min}$ on ice. Four microliters of $100 \mathrm{mM}$ sodium acetate and $6 \mathrm{~mL}$ of chloroform were added, and extracts were centrifuged at $4600 \mathrm{rpm}$ for $30 \mathrm{~min}$. Aqueous phases were removed and subjected to ethanol precipitation. Precipitated RNA were resuspended in buffer A (10 mM Tris- $\mathrm{HCl}$ at $\mathrm{pH} 8,400 \mathrm{mM} \mathrm{NaCl}$ ) and loaded onto a 13mL 15Q chromatography column connected to an ÄKTA pure system (GE Healthcare). RNAs were then eluted with a linear gradient of $\mathrm{NaCl}$ (buffer $\mathrm{B}, 10 \mathrm{mM}$ Tris- $\mathrm{HCl}$ at $\mathrm{pH} 8,700 \mathrm{mM} \mathrm{NaCl}$ ). Gel filtration was then performed on the eluted fractions containing the 5S RNA using buffer $\mathrm{C}(10 \mathrm{mM}$ Tris- $\mathrm{HCl}$ at $\mathrm{pH} 8,150 \mathrm{mM}$ $\mathrm{NaCl}$ ) on a Superdex 200 16/60 (GE Healthcare).

\section{Immunoprecipitations}

Immunoprecipitations using the ProtA tag on IgG sepharose beads were performed as described before (Lebaron et al. 2005).

\section{EMSAs}

5S RNA was purified from yeast, dephosphorylated, labeled with ${ }^{32} \mathrm{P}$ at the $5^{\prime}$ end, and purified on G50 column. Labeled RNA $(0.1$ $\mathrm{nM}$ ) was incubated with protein in a $10-\mu \mathrm{L}$ reaction containing 10 $\mathrm{mM}$ Tris- $\mathrm{HCl}$ (pH 7.6), $100 \mathrm{mM} \mathrm{KCl}, 5 \mathrm{mM} \mathrm{MgCl}_{2}, 1$ mM DTT, 1 $\mathrm{mM}$ EDTA, and $5 \%$ glycerol for $10 \mathrm{~min}$ at room temperature. The reactions were resolved in 5\% native polyacrylamide gels running in $0.5 \times \mathrm{TBE}(\mathrm{pH} 7.8)$ buffer at $4^{\circ} \mathrm{C}$. The gels were dried and autoradiographed using a BAS-5000 PhosphorImager (Fugi).

\section{$C D$}

CD spectra were recorded using a Jobin-Yvon Mark VI circular dichrograph at a scan speed of $0.2 \mathrm{~nm} / \mathrm{sec}$. Quartz spare split-compartment cuvettes with a $0.437-\mathrm{cm}$ path length per compartment were used. The relevant protein solution was placed in one compartment of the cuvette, and the RNA target solution was placed in the other one. The CD spectra were recorded before and after mixing the cuvette contents. Blanks were run before each spectrum and subtracted from the raw data. Three spectra were averaged to increase the signal to noise ratio. The final protein and/or RNA concentration was $1 \mu \mathrm{M}$ in $10 \mathrm{mM}$ Tris- $\mathrm{HCl}$ buffer $(\mathrm{pH}$ 8) containing $150 \mathrm{mM} \mathrm{NaCl}$, and the assays were carried out at $20^{\circ} \mathrm{C}$. The protein and RNA spectra alone were recorded by replacing one or the other compartment by buffer. The results are presented as normalized $\Delta \varepsilon$ values on the basis of the nucleotide mean residue mass of $330 \mathrm{Da}$. Taking into account a sensitivity of $\delta(\Delta \mathrm{A})=10^{-6}$ for the apparatus, the nucleotide concentration, and the optical path length of the cuvette, measurements were obtained at a precision of $\delta(\Delta \varepsilon)= \pm 0.01 \mathrm{M}^{-1} \mathrm{~cm}^{-1}$ per nucleotide. 


\section{Filter-binding assay}

The fluorescently $5^{\prime}$ IRD800-labeled RNA was ordered to IDT. After reception, the RNA was heated for $2 \mathrm{~min}$ at $65^{\circ} \mathrm{C}$, immediately placed for $10 \mathrm{~min}$ on ice, and diluted in binding buffer containing $1 \times \mathrm{PBS}(\mathrm{pH} 7.6), 2 \mathrm{mM} \mathrm{MgCl} 2,6 \%$ glycerol, $0.5 \mathrm{mM}$ DTT, $0.1 \mathrm{mM}$ EDTA, $5 \mu \mathrm{g}$ of E. coli tRNA per milliliter, and $50 \mu \mathrm{g}$ of BSA per milliliter. Binding reactions consisted of $10 \mu \mathrm{L}$ of RNA at $0.5 \mathrm{nM}$ and $5 \mu \mathrm{L}$ of proteins (final concentration from 25 to $2000 \mathrm{nM}$ ). Binding reactions were incubated for 15 min at $20^{\circ} \mathrm{C}$ and then applied directly to filters containing the two membranes under gentle vacuum. Before and after application of the binding reactions, $200 \mu \mathrm{L}$ of binding buffer was used to equilibrate and rinse the system. Binding was quantified using an Odyssey apparatus (Li-Cor) and Image Lite program (Li-Cor). The intensity was corrected for background and fit for $K_{\mathrm{d}}$ using Gnuplot (http://www.gnuplot.info) using the following equation: $f(x)=x /\left(x+K_{d}\right)$, where $x$ is the concentration of protein.

\section{Cross-linking and analysis of Torrent sequence data}

Cells expressing Rpf2-HTP, Rrs1-HTP, or wild type were grown to an $\mathrm{OD}_{600}$ of 0.5 in synthetic dextrose (SD) medium lacking Trp and Ura with $2 \%$ glucose. Cells were directly cross-linked inside culture media using Megatron (Granneman et al. 2011). Cells were processed as previously described (Granneman et al. 2009). Torrent sequencing data were aligned to yeast genome using TMAP (http://www.iontorrent.com). Downstream analyses, including the pileups presented here, were performed using the pyCRAC tool suite (Webb et al. 2014).

\section{SAXS data collection}

SAXS data on S. cerevisiae free 5S RNA were collected on beamline SWING (Soleil Synchrotron) at an energy of $13 \mathrm{keV}$. SAXS data on the Rpf2-Rrs1 protein complex and the 5S-Rpf2-Rrs1 RNA-protein complex, either full-length or proteolyzed, were collected on beamline BM29 (ESRF) at an energy of $12.5 \mathrm{keV}$. Scattering data were collected at $20^{\circ} \mathrm{C}$ at sample concentrations between 1 and $25 \mathrm{mg} / \mathrm{mL}$. For measurement on the 5S RNA at SWING, the sample was injected on a gel filtration column (bio-SEC 3, Agilent), and data were recorded on the in-line elution profile (David and Perez 2009). For proteins and protein-RNA complexes, samples were injected directly on the BM29 flow cell (Pernot et al. 2013). Buffer background scattering was collected on the gel filtration buffers used for the RNA, proteins, and RNA-protein complexes. Background subtraction, averaging, and scaling were carried out using Foxtrot on the SWING beamline or the EDNA pipeline available on the BM29 beamline.

\section{SAXS data processing}

Further processing and data analysis were done using the programs of the ATSAS suite (Petoukhov et al. 2012). Guinier analysis was carried out in PRIMUS on data in the scattering range consistent with $Q_{\max } \times \mathrm{Rg}<1.3$. Distance distribution functions and $D_{\max }$ were determined using the program Gnom. Ab initio free atom modeling was performed using the program DAMMIF protein complex. For RNA-protein complexes, the multiphase approach implemented in MONSA was used for shape modeling using the information from free RNA, Rpf2-Rrs1 alone, and RNA-protein complexes. Multiple MONSA calculations were run on the ATSAS online server. Several models (20-50) were computed for each macromolecule. Superposition, averaging, filtering, and computation of normalized spatial discrepancies
(NSDs) were done using the program DAMAVER for each model ensemble.

\section{Molecular modelling}

The missing parts of the proteins were modeled by an ab initio approach using Rosetta (Rohl et al. 2004). Structures of each missing domain were calculated with Rosetta and clustered with a root mean square deviation (RMSD) radius of $5 \AA$. The top cluster as each domain was included as a template for homology modeling with Modeller for full atom model generation (Sali and Blundell 1993). The structures calculated with Modeller were ranked by the DOPE score (Shen and Sali 2006). SAXS data were then used for further modeling with DADIMODO (Evrard et al. 2011). The free RNA structure was modeled by generating 2000 models based only on secondary structure restraints using MC-SYM (Parisien and Major 2008). This data set explored a wide range of $5 \mathrm{~S}$ RNA structures in both the structure of each helix and the relative orientation of the helices of the three-way junction. The RNA-protein complexes were modeled by superposing the structure of the protein complex in the same orientation as the cryoEM bound model on all of the RNA structures generated. For each model, the goodness of fit was estimated by $\chi^{2}$ calculation with Crysol.

\section{Accession numbers}

The Gene Expression Omnibus accession number for all sequence data reported in this study is GSE68431. The structure of the Rpf2-Rrs1 complex was deposited at the Protein Data Bank under code $5 \mathrm{a} 53$.

\section{Acknowledgments}

We thank Professor Nicolas James Watkins from Newcastle University for his careful reading of the manuscript and fruitful suggestions. We thank Dr. Frank Letourneur for his technical support on deep-sequencing analysis. Work at Université Paris Descartes was supported by Centre National de la Recherche Scientifique, University Paris Descartes, the RNPGenesis grant from the Agence Nationale de la Recherche (ANR JC RNPGenesis), and the Institut Universitaire de France. We acknowledge SOLEIL and ESRF for provision of synchrotron radiation facilities and thank the beamline scientists on the PROXIMA I and II, SWING, and BM29 beamlines. C.M. and S.L. expressed, purified, and crystallized the Rpf2 complex. C.M., N.L., and S.R. solved the crystal structure. S.L., M.B., L.D., and C.M. performed RNA- and protein-binding assays. S.R., M.B., N.L., S.L., and C.M. performed the SAXS experiments. S.L., J.P., and E.P. performed the CRAC experiments. N.L. designed the studies, interpreted data, and wrote the paper with contributions from S.L., C.M., M.B., and S.R.

\section{References}

Adams PD, Afonine PV, Bunkóczi G, Chen VB, Davis IW, Echols N, Headd JJ, Hung L-W, Kapral GJ, Grosse-Kunstleve RW, et al. 2010. Phenix: a comprehensive Python-based system for macromolecular structure solution. Acta Crystallogr D Biol Crystallogr 66: 213-221.

Armistead J, Khatkar S, Meyer B, Mark BL, Patel N, Coghlan G, Lamont RE, Liu S, Wiechert J, Cattini PA, et al. 2009. Mutation of a gene essential for ribosome biogenesis, EMG1, causes Bowen-Conradi syndrome. Am I Hum Genet 84: 728-739. 
Asano N, Kato K, Nakamura A, Komoda K, Tanaka I, Yao M. 2015. Structural and functional analysis of the Rpf2-Rrs1 complex in ribosome biogenesis. Nucleic Acids Res 43: 47464757.

Baßler J, Paternoga H, Holdermann I, Thoms M, Granneman S, Barrio-Garcia C, Nyarko A, Stier G, Clark SA, Schraivogel $\mathrm{D}$, et al. 2014. A network of assembly factors is involved in remodeling rRNA elements during preribosome maturation. I Cell Biol 207: 481-498.

Bricogne G, Vonrhein C, Flensburg C, Schiltz M, Paciorek W. 2003. Generation, representation and flow of phase information in structure determination: recent developments in and around Sharp 2.0. Acta Crystallogr D Biol Crystallogr 59: 2023-2030.

Bugner V, Tecza A, Gessert S, Kühl M. 2011. Peter Pan functions independently of its role in ribosome biogenesis during early eye and craniofacial cartilage development in Xenopus laevis. Development 138: 2369-2378.

Calviño FR, Kharde S, Ori A, Hendricks A, Wild K, Kressler D, Bange G, Hurt E, Beck M, Sinning I. 2015. Symportin 1 chaperones 5S RNP assembly during ribosome biogenesis by occupying an essential rRNA-binding site. Nat Commun 6: 6510.

Ciganda M, Williams N. 2011. Eukaryotic 5S rRNA biogenesis. Wiley Interdiscip Rev RNA 2: 523-533.

David G, Perez J. 2009. Combined sampler robot and high-performance liquid chromatography: a fully automated system for biological small-angle X-ray scattering experiments at the Synchrotron SOLEIL SWING beamline. I Appl Crystallogr 42: 892-900.

Donati G, Peddigari S, Mercer CA, Thomas G. 2013. 5S ribosomal RNA is an essential component of a nascent ribosomal precursor complex that regulates the Hdm2-p53 checkpoint. Cell Rep 4: 87-98.

Emsley P, Cowtan K. 2004. Coot: model-building tools for molecular graphics. Acta Crystallogr D Biol Crystallogr 60: 21262132.

Evrard G, Mareuil F, Bontems F, Sizun C, Perez J. 2011. DADIMODO: a program for refining the structure of multidomain proteins and complexes against small-angle scattering data and NMR-derived restraints. I Appl Crystallogr 44: 12641271.

Furtado C, Regis-da-Silva CG, Passos-Silva DG, Franco GR, Macedo AM, Junho Pena SD, Machado CR. 2007. Schistosoma mansoni: the IMP4 gene is involved in DNA repair/tolerance after treatment with alkylating agent methyl methane sulfonate. Exp Parasitol 116: 25-34.

Gamalinda M, Ohmayer U, Jakovljevic J, Kumcuoglu B, Woolford J, Mbom B, Lin L, Woolford JL. 2014. A hierarchical model for assembly of eukaryotic 60S ribosomal subunit domains. Genes Dev 28: 198-210.

Gambe AE, Matsunaga S, Takata H, Ono-Maniwa R, Baba A, Uchiyama S, Fukui K. 2009. A nucleolar protein RRS1 contributes to chromosome congression. FEBS Lett 583: 19511956.

Gérczei T, Correll CC. 2004. Imp3p and Imp4p mediate formation of essential U3-precursor rRNA (pre-rRNA) duplexes, possibly to recruit the small subunit processome to the prerRNA. Proc Natl Acad Sci 101: 15301-15306.

Granneman S, Kudla G, Petfalski E, Tollervey D. 2009. Identification of protein binding sites on U3 snoRNA and pre-rRNA by UV cross-linking and high-throughput analysis of cDNAs. Proc Natl Acad Sci 106: 9613-9618.

Granneman S, Petfalski E, Tollervey D. 2011. A cluster of ribosome synthesis factors regulate pre-rRNA folding and $5.8 \mathrm{~S}$
rRNA maturation by the Rat1 exonuclease. EMBO I 30: 4006-4019.

Kabsch W. 2010. XDS. Acta Crystallogr D Biol Crystallogr 66: 125-132.

Knight E, Darnell JE. 1967. Distribution of 5 s RNA in HeLa cells. J Mol Biol 28: 491-502.

Layat E, Probst AV, Tourmente S. 2013. Structure, function and regulation of transcription factor IIIA: from Xenopus to Arabidopsis. Biochim Biophys Acta 1829: 274-282.

Lebaron S, Froment C, Fromont-Racine M, Rain J-C, Monsarrat B, Caizergues-Ferrer M, Henry Y. 2005. The splicing ATPase prp43p is a component of multiple preribosomal particles. Mol Cell Biol 25: 9269-9282.

Lebaron S, Schneider C, van Nues RW, Swiatkowska A, Walsh D, Böttcher B, Granneman S, Watkins NJ, Tollervey D. 2012. Proofreading of pre-40S ribosome maturation by a translation initiation factor and 60S subunits. Nat Struct Mol Biol 19: 744-753.

Lee BM, Xu J, Clarkson BK, Martinez-Yamout MA, Dyson HJ, Case DA, Gottesfeld JM, Wright PE. 2006. Induced fit and 'lock and key' recognition of 5S RNA by zinc fingers of transcription factor IIIA. J Mol Biol 357: 275-291.

Leidig C, Thoms M, Holdermann I, Bradatsch B, Berninghausen O, Bange G, Sinning I, Hurt E, Beckmann R. 2014. 60 S ribosome biogenesis requires rotation of the $5 \mathrm{~S}$ ribonucleoprotein particle. Nat Commun 5: 3491.

Leslie AG, Powell HR. 2007. Processing diffraction data with Mosflm. In Evolving methods for macromolecular crystallography (ed. Read R, Sussman JL), pp. 41-51. Springer, Dordrecht, The Netherlands.

Liu Y, He Y, Jin A, Tikunov AP, Zhou L, Tollini LA, Leslie P, Kim T-H, Li LO, Coleman RA, et al. 2014. Ribosomal proteinMdm2-p53 pathway coordinates nutrient stress with lipid metabolism by regulating MCD and promoting fatty acid oxidation. Proc Natl Acad Sci 111: E2414-E2422.

Loc'h J, Blaud M, Réty S, Lebaron S, Deschamps P, Bareille J, Jombart J, Robert-Paganin J, Delbos L, Chardon F, et al. 2014. RNA mimicry by the Fap7 adenylate kinase in ribosome biogenesis. PLOS Biol 12: e1001860.

Longtine MS, McKenzie A, Demarini DJ, Shah NG, Wach A, Brachat A, Philippsen P, Pringle JR. 1998. Additional modules for versatile and economical PCR-based gene deletion and modification in Saccharomyces cerevisiae. Yeast 14: 953-961.

Lu D, Alexandra Searles M, Klug A. 2003. Crystal structure of a zinc-finger-RNA complex reveals two modes of molecular recognition. Nature 426: 96-100.

Matsuo Y, Granneman S, Thoms M, Manikas R-G, Tollervey D, Hurt E. 2014. Coupled GTPase and remodelling ATPase activities form a checkpoint for ribosome export. Nature 505: $112-116$.

Miliani de Marval PL, Zhang Y. 2011. The RP-Mdm2-p53 pathway and tumorigenesis. Oncotarget 2: 234-238.

Narla A, Ebert BL. 2011. Translational medicine: ribosomopathies. Blood 118: 4300-4301.

Ng CL, Waterman D, Koonin EV, Antson AA, Ortiz-Lombardía M. 2005. Crystal structure of Mil (Mth680): internal duplication and similarity between the Imp4/Brix domain and the anticodon-binding domain of class IIa aminoacyl-tRNA synthetases. EMBO Rep 6: 140-146.

Parisien M, Major F. 2008. The MC-sold and MC-sym pipeline infers RNA structure from sequence data. Nature 452: 51-55.

Pernot P, Round A, Barrett R, De Maria Antolinos A, Gobbo A, Gordon E, Huet J, Kieffer J, Lentini M, Mattenet M, et al. 2013. Upgraded ESRF BM29 beamline for SAXS on macromolecules in solution. J Synchrotron Radiat 20: 660-664. 
Petoukhov MV, Franke D, Shkumatov AV, Tria G, Kikhney AG, Gajda M, Gorba C, Mertens HD, Konarev PV, Svergun DI. 2012. New developments in the ATSAS program package for small-angle scattering data analysis. I Appl Crystallogr 45: 342-350.

Pettersen EF, Goddard TD, Huang CC, Couch GS, Greenblatt DM, Meng EC, Ferrin TE. 2004. UCSF Chimera-a visualization system for exploratory research and analysis. I Comput Chem 25: 1605-1612.

Rohl CA, Strauss CEM, Misura KMS, Baker D. 2004. Protein structure prediction using Rosetta. Methods Enzymol 383: 66-93.

Sali A, Blundell TL. 1993. Comparative protein modelling by satisfaction of spatial restraints. J Mol Biol 234: 779-815.

Sasaki M, Kawahara K, Nishio M, Mimori K, Kogo R, Hamada K, Itoh B, Wang J, Komatsu Y, Yang YR, et al. 2011. Regulation of the MDM2-P53 pathway and tumor growth by PICT1 via nucleolar RPL11. Nat Med 17: 944-951.

Shen M-Y, Sali A. 2006. Statistical potential for assessment and prediction of protein structures. Protein Sci 15: 2507-2524.

Sloan KE, Bohnsack MT, Watkins NJ. 2013. The 5S RNP couples p53 homeostasis to ribosome biogenesis and nucleolar stress. Cell Rep 5: 237-247.

Sondalle SB, Baserga SJ. 2014. Human diseases of the SSU processome. Biochim Biophys Acta 1842: 758-764.
Steitz JA, Berg C, Hendrick JP, La Branche-Chabot H, Metspalu A, Rinke J, Yario T. 1988. A 5S rRNA/L5 complex is a precursor to ribosome assembly in mammalian cells. I Cell Biol 106: 545-556.

Strunk BS, Novak MN, Young CL, Karbstein K. 2012. A translation-like cycle is a quality control checkpoint for maturing 40S ribosome subunits. Cell 150: 111-121.

Trabuco LG, Villa E, Mitra K, Frank J, Schulten K. 2008. Flexible fitting of atomic structures into electron microscopy maps using molecular dynamics. Structure 16: 673-683.

Ulbrich C, Diepholz M, Baßler J, Kressler D, Pertschy B, Galani K, Böttcher B, Hurt E. 2009. Mechanochemical removal of ribosome biogenesis factors from nascent $60 \mathrm{~S}$ ribosomal subunits. Cell 138: 911-922.

Webb S, Hector RD, Kudla G, Granneman S. 2014. PAR-CLIP data indicate that Nrd1-Nab3-dependent transcription termination regulates expression of hundreds of protein coding genes in yeast. Genome Biol 15: R8.

Wehner KA, Baserga SJ. 2002. The 670 -like motif: a eukaryotic RNA binding domain unique to a superfamily of proteins required for ribosome biogenesis. Mol Cell 9: 329-339.

Zhang J, Harnpicharnchai P, Jakovljevic J, Tang L, Guo Y, Oeffinger M, Rout MP, Hiley SL, Hughes T, Woolford JL. 2007. Assembly factors Rpf2 and Rrs1 recruit 5S rRNA and ribosomal proteins rpL5 and rpL11 into nascent ribosomes. Genes Dev 21: 2580-2592. 


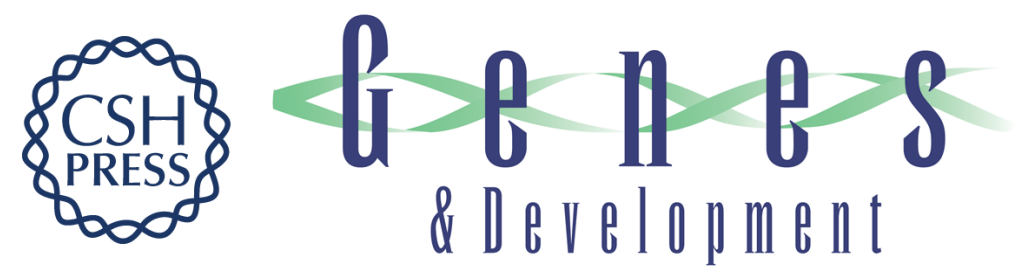

\section{Chaperoning 5S RNA assembly}

Clément Madru, Simon Lebaron, Magali Blaud, et al.

Genes Dev. 2015, 29:

Access the most recent version at doi:10.1101/gad.260349.115

Supplemental Material

References

Creative Commons License

Email Alerting Service
http://genesdev.cshlp.org/content/suppl/2015/07/09/29.13.1432.DC1

This article cites 50 articles, 12 of which can be accessed free at: http://genesdev.cshlp.org/content/29/13/1432.full.html\#ref-list-1

This article is distributed exclusively by Cold Spring Harbor Laboratory Press for the first six months after the full-issue publication date (see

http://genesdev.cshlp.org/site/misc/terms.xhtml). After six months, it is available under a Creative Commons License (Attribution-NonCommercial 4.0 International), as described at http://creativecommons.org/licenses/by-nc/4.0/.

Receive free email alerts when new articles cite this article - sign up in the box at the top right corner of the article or click here.

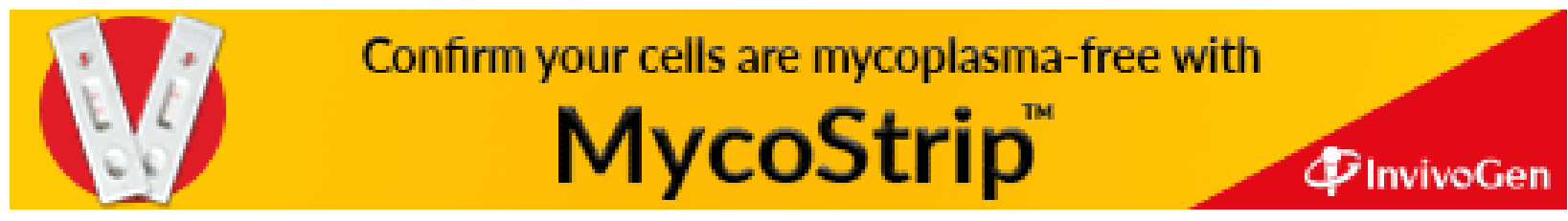

